$\begin{array}{llll}\text { Submission: 30/07/2020; } & 1^{\text {st }} \text { round notif.: 13/10/2020; } & \text { New version: 23/10/2020; } & 2^{\text {nd }} \text { round notif.: 09/11/2020; } \\ \text { Camera ready: 12/11/2020; } & \text { Edition review: 11/12/2020; } & \text { Available online: 14/12/2020; }\end{array}$

\title{
Sala de aula 4.0 - Uma Proposta de Ensino Remoto Baseado em Sala de Aula Invertida, Gamification e PBL
}

\author{
Title: Classroom 4.0 - A remote teaching proposal based on flipped classroom, gamification, \\ and PBL
}

João Lucas dos Santos Oliveira Universidade Federal de Goiás joaooliveira@discente.ufg.br

Amanda Vitória Silva Fonseca Instituto Nordeste de Educação Superior e Pós-Graduação amandavitoriaff@gmail.com

\author{
Priscila da Silva Neves Lima \\ Universidade Federal de Goiás \\ priscila_lima@ufg.br
}

\author{
Cedric Luiz de Carvalho \\ Universidade Federal de Goiás \\ cedric@ufg.br
}

\begin{abstract}
Resumo
Os crescentes avanços tecnológicos e o fácil acesso às novas tecnologias levaram à mudanças significativas na sociedade, as quais agora se refletem na educação. Com o objetivo de melhorar o processo de aprendizagem, contribuindo com o aprimoramento das metodologias de ensino, este artigo apresenta o uso de técnicas de sala de aula invertida, aprendizagem baseada em projetos, trabalho em grupo e gamification em um curso de Inteligência Artificial. A metodologia apresentada aqui foi alcançada através de experimentações e mudanças incrementais definidas a partir das opiniões dos alunos e dos resultados produzidos por eles. Uma quarta abordagem é sugerida para atender a demanda por aulas remotas durante o periodo de pandemia da COVID-19. Essa proposta foi construída a partir das experiências obtidas nas abordagens anteriores. Os resultados preliminares mostraram uma melhora nas notas dos alunos, além de estimular o pensamento crítico e o uso de conceitos teóricos na resolução de problemas práticos durante as aulas, melhorando o uso de pensamentos de primeira ordem, conforme definido pela Taxonomia de Bloom. Os resultados são encorajadores e nos permitiram refletir como a nova geração de alunos está aprendendo e as melhores práticas para construir conhecimento em sala de aula.
\end{abstract}

Palavras-Chave: Sala de aula invertida, Gamificação, $P B L$

\begin{abstract}
Increasing technological advances and easy access to new technologies have led to significant changes in society that are now reflected in education. In order to improve the learning process and the best teaching methodologies, this article presents the use of flipped classroom techniques, project-based learning, group work and gamification in an Artificial Intelligence course. The proposed methodology was achieved through three different approaches in Computer Science courses for higher education students. The changes were defined by a feedback process from students from different groups, who pointed out the strengths and weaknesses of the approach adopted. A fourth approach is suggested in order to meet the demand for remote classes during the pandemic period, which was only possible through the experiences obtained in previous approaches. Preliminary results showed an improvement in students' grades, in addition to stimulating critical thinking and the use of theoretical concepts in solving practical problems during classes, improving the use of first-order thoughts, as defined by Bloom's Taxonomy. The results are encouraging and have allowed us to rethink how the new generation of students is learning and the best practices for building knowledge in classroom.
\end{abstract}

Keywords: Flipped-Classroom, Gamification, PBL

Cite as: Oliveira, J. L. S.; Lima, P. S. N.; de Carvalho, C. L. \& Fonseca, A. V. S. (2020). Classroom 4.0 - A remote teaching proposal based on flipped classroom, gamification, and PBL (Sala de aula 4.0 - Uma proposta de Ensino remoto baseado em sala de aula invertida, gamification e PBL). Brazilian Journal of Computers in Education (Revista Brasileira de Informática na Educação - RBIE), 28, 909-933. DOI: 10.5753/RBIE.2020.28.0.909 


\section{Introdução}

O ano é 2020 e, desde o seu início, o mundo está em pausa por conta do novo coronavirus (SarsCov-2). Os coronavírus são uma grande família de vírus que podem causar doenças em animais ou humanos. O coronavírus descoberto mais recentemente causa a doença COVID-19 (WHO, 2020). Esse vírus é altamente infeccioso e as recomendações da Organização Mundial da Saúde (OMS) para evitar sua disseminação envolvem, entre outras coisas, evitar aglomerações, isolamento social e distanciamento físico. Assim, setores como educação, economia, e saúde pública enfrentam os desafios de uma nova realidade imposta pelo vírus.

A educação, em especial, deve encontrar novos meios efetivos e de qualidade para o seu desenvolvimento nesse cenário. Desde janeiro de 2020 (no Brasil a crise começou em março), assim como outros setores, o sistema educacional foi interrompido. E, na circunstância atual, é impossível reunir cerca de 40 ou mais alunos em uma sala de aula. A tecnologia é agora a maior (ou não) aliada (para não dizer a única) do professor para dar prosseguimento às aulas que antes eram ministradas presencialmente.

A boa notícia é que o ensino é um organismo vivo e está em constante transformação, caminha e se molda às características do conteúdo e do educando, evolui e se aperfeiçoa no tempo (Nicésio, Almeida, \& Conceição, 2015). Seguramente, por isso, novas metodologias e técnicas são estudadas constantemente na perspectiva de aprimorar e oferecer diversos meios de aprendizagem aos alunos. Em uma sociedade em que a aprendizagem sofre o impacto das tecnologias, nada mais natural do que a incorporação de tecnologias da informação e comunicação (TIC) na educação.

O uso de vários sistemas digitais no cotidiano dos alunos é uma realidade e tem se mostrado útil no processo de ensino-aprendizagem (Savi \& Ulbricht, 2008). O ensino a distância é um exemplo claro desse conceito, expandindo vários recursos pedagógicos disponíveis na Internet, facilitando o acesso à informação e possibilitando um aprendizado autônomo e distinto aos mais diferentes perfis. Iniciativas como a Khan Academy ${ }^{l}$, fundada em 2006, visam promover uma educação global de qualidade para todos, em qualquer lugar. Projetos que oferecem cursos online abertos e em grande escala, do inglês Massive Open Online Course (MOOC) em plataformas como Udacity ${ }^{2}$, Coursera ${ }^{3}$, FutureLearn $^{4}$, edX ${ }^{5}$ e Stanford Online ${ }^{6}$, abriram as portas para uma geração de estudantes mais independentes e proativos.

Nessa linha, o uso de técnicas como a aprendizagem baseada em projetos, do inglês ProjectBased Learning (PBL) foram introduzidas nas salas de aula para melhorar as habilidades de resolução de problemas dos alunos. A PBL é uma abordagem de aprendizagem orientada pelo aluno e facilitada pelo professor (Bell, 2010). Nessa abordagem, os alunos trabalham em grupos para resolver problemas desafiadores que são autênticos, baseado no currículo e frequentemente interdisciplinar. Os alunos decidem como abordar um problema e quais atividades perseguir. Ao longo deste processo, o papel do professor é orientar e aconselhar, ao invés de dirigir e gerenciar, o trabalho do aluno (Solomon, 2003).

Em (Anazifa \& Djukri, 2017), os autores utilizam uma abordagem integrada, baseada em problemas e projetos, no ensino de matemática e ciências naturais. Neste caso, o estudo investigou a diferença entre a aprendizagem baseada em projetos e a aprendizagem baseada em problemas na criatividade e no pensamento crítico do aluno. É possível afirmar que o uso de PBL poderesultar

\footnotetext{
${ }^{1}$ https://pt.khanacademy.org/

${ }^{2}$ https://www.udacity.com/

${ }^{3}$ https://es.coursera.org/

${ }^{4}$ https://www.futurelearn.com/

${ }^{5} \mathrm{https}: / /$ www.edx.org/

${ }^{6}$ https://online.stanford.edu/courses
} 
em melhora no desempenho dos alunos, podendo estar relacionado à participação ativa do aluno no processo de ensino-aprendizagem como descrito em (Ergül \& Kargın, 2014). Além disso, há indicações de melhorias em várias habilidades, como abstração e resolução de problemas, comunicação, argumentação, responsabilidade e trabalho em grupo (Nuutila, Törmä, \& Malmi, 2005).

A PBL é apenas uma das abordagens propostas para promover resultados efetivos em sala de aula. Há outros modelos pedagógicos voltados para o sucesso acadêmico dos estudantes (Rahman, Aris, Mohamed, \& Zaid, 2014). A exemplo, a sala de aula invertida, do inglês Flipped Classrom (FC), é um modelo de aprendizado que tem como alvo atividades de construção de conhecimento centradas no aluno no ambiente escolar (Lai \& Hwang, 2016). Em uma aula invertida, é possível trazer para a sala de aula atividades relacionadas a processos de aprendizagem cognitiva de ordem superior (uso de conhecimento, análise, síntese e avaliação), permitindo que atividades cognitivas de ordem inferior (aquisição de conhecimento e entendimento) sejam realizadas fora da sala de aula, promovendo também o ensino personalizado de acordo com o perfil do aluno (Conklin, 2005).

A técnica de inverter a sala de aula baseia-se nos conceitos de metodologia ativa (o aluno deve tomar a iniciativa de controlar seus estudos), proporcionando envolvimento do aluno, educação híbrida (metodologia que combina aulas online e presenciais, mesclando conteúdo complementar), além de aulas de gamification e aulas em vídeo (Pierce \& Fox, 2012). O primeiro modelo de sala de aula invertida foi proposto por professores de química da Woodland Park High School (Bergmann \& Sams, 2012). E o sucesso da aplicação desta ténica depende principalmente do que os autores chamam de autorregulação (Mason, Shuman, \& Cook, 2013; Berrett, 2012), que está diretamente ligada ao comprometimento e disciplina do aluno.

A disponibilidade de material didático digital de alta qualidade permite que os alunos estabeleçam seu próprio ritmo de estudo. Porém, caso estes não consigam se organizar entre os períodos de estudo e a aplicação prática em sala de aula, provavelmente não obterão bons resultados (Sun, Wu, \& Lee, 2017). Essa disponibilidade de material didático digital é eficaz pois, dentre outros motivos, alguns estudos mostram que as videoaulas são ligeiramente melhores do que as sessões regulares em sala de aula no que se refere à transmissão de conhecimento (Carter, 2009; Jong, 2017) e, em alguns casos, as aulas interativas promovem melhores resultados (Zhang, Zhou, Briggs, \& Nunamaker Jr, 2006).

O contratempo está na disponibilização do material por si só, sabemos que a modalidade de ensino integralmente a distância é estudada há muito tempo e os professores, em geral, não têm formação para atuar nela. Pode ser que quando superarmos essa pandemia, muitos professores voltarão ao formato antigo de ensino. Por isso, o melhor seria encarar esse momento como o de uma "educação remota emergencial". E dentre as possibilidades de trabalhar com metodologias ativas e a utilização de tecnologias, a sala de aula invertida é uma das que mais se adaptam às necessidades atuais da educação a distância - considerando que, em tempos de distanciamento social, a sala de aula é a tela do seu computador.

Nesse caso, a técnica de sala de aula invertida é um processo que não depende unicamente de um ator (aluno ou professor), mas sim um trabalho colaborativo onde o professor não é um transmissor de conhecimento, mas sim o facilitador, orientando os alunos que se comprometem a estudar fora da sala de aula. Em uma avaliação preliminar, com a aplicação da metodologia em uma turma do primeiro período e outra do oitavo período, foi possível observar que os alunos de primeiro período têm se adaptado melhor às aulas remotas. Talvez por não estarem ainda habituados à rotina das aulas na universidade.

Portanto, este artigo tem como objetivo contribuir com as instituições de ensino, pesquisadores e órgãos governamentais, oferecendo sugestões baseadas em estudos de caso, para a condução das 
aulas remotas durante o período emergencial de pandemia.

Este trabalho apresenta um projeto que foi implementado em grupos de estudantes de graduação do curso de Ciência da Computação, visando melhorar o desempenho dos alunos com o uso de técnicas de sala de aula invertida e técnicas de autorregulação. Outras técnicas foram usadas como partes complementares do processo pedagógico, como trabalho em grupo, PBL e gamification. Considerando a atual conjuntura, sugerimos uma nova abordagem capaz de atender as demandas para as aulas remotas, utilizando sala de aula invertida com adaptações ao novo contexto de pandemia da COVID-19.

Este artigo está estruturado em 5 seções. $\mathrm{Na}$ seção 2, apresentamos alguns trabalhos relacionados. Na seção 3, descrevemos a organização da disciplina em que a metodologia foi aplicada. Na seção 4, são descritos os principais resultados obtidos. Na seção 5, são apresentadas algumas limitações da última abordagem proposta. Por fim, na seção 6, são apresentadas nossas considerações finais.

\section{Trabalhos Relacionados}

Estudos envolvendo sala de aula invertida são relativamente novos, de acordo com a revisão sistemática da literatura apresentada em (Akçayır \& Akçayır, 2018). Este trabalho apresenta um estudo em larga escala sobre sala de aula invertida e tem o objetivo de examinar suas vantagens e desafios relatados por alunos e instrutores. Há registro de estudos publicados no ano 2000, porém, a maior quantidade de trabalhos ocorre a partir do ano de 2016 e segue crescente em 2017 e 2018 (Koh, 2019).

São diversos os objetivos de pesquisa sobre sala de aula invertida. Há pesquisas relevantes sobre aplicações dessa metodologia, suas conexões com outras áreas pedagógicas e resultados obtidos em diferentes contextos. Há também trabalhos que relatam experiências positivas sobre a melhoria do desempenho do aluno (O'Flaherty \& Phillips, 2015). Alguns estudos como (Mokmin, Masood, \& Osman, 2019), relatam experiências que ocorreram durante a implementação da sala de aula invertida.

Para alguns experimentos como (Wolf, Wilhelm-Weidner, \& Nestmann, 2018), a metodologia foi aplicada para ensinar conceitos teóricos de Ciência da Computação a estudantes do ensino médio e obteve resultados satisfatórios. Em (Rutherfoord \& Rutherfoord, 2013), os autores com o sugestivo título "Flipping the Classroom - Is It For You?" descrevem as melhores e piores práticas do método para que um professor, ao aplicá-las, possa obter uma implementação bem-sucedida.

Essa metodologia ativa de sala de aula invertida, pode envolver muitas técnicas a fim de apoiar o processo de aprendizado e a construção de conhecimento do aluno. Um exemplo disso é (Govindaraj \& Silverajah, 2017; Gibbons, 2013), onde os métodos foram utilizados em conjunto com técnicas de rotação de estados e técnicas baseadas em Game Design, respectivamente. Há ainda (Latulipe, Long, \& Seminario, 2015), que uniu sala de aula invertida a aplicação de técnicas de gamification e de trabalho em grupo para engajar e melhorar o desempenho dos alunos na disciplina CS1. A CS1 aborda assuntos introdutórios de cursos de Ciência da Computação que são a chave para o sucesso do aluno no curso (Hertz, 2010). Há também outras pesquisas focadas em CS1, como a de (Ambrósio \& Costa, 2010), relatando os resultados de um projeto que combina o uso da tecnologia de computação móvel baseada em caneta e a aprendizagem baseada em problemas no redesenho de um curso introdutório de programação de computadores. Como resultado, os autores obtiveram um aumento na motivação dos alunos com uma queda significativa no número de desistências e faltas.

A combinação de sala de aula invertida com outras técnicas também está presente na pesquisa 
de (Baepler, Walker, \& Driessen, 2014), que reduziram o tempo da sala de aula em dois terços, disponibilizando as aulas online e convertendo o tempo para uma sala de aula mais ativa, com perguntas, explicações e demonstrações junto ao professor. Em (Argaw, Haile, Ayalew, \& Kuma, 2017), os autores aplicaram as técnicas de PBL vistas em (Barrows, Tamblyn, et al., 1980) com os alunos da décima segunda série da escola preparatória Wachemo.

As abordagens que utilizam trabalhos em grupos, como pode ser visto em (Lo \& Hew, 2017), são mais frequentes que outras técnicas, incluindo materiais de texto, anotações, exercícios online, discussão online, questionários, revisão breve, palestra curta, práticas individuais, atividades em pequenos grupos, apresentação e autoavaliação do aluno. Isso pode demonstrar que a interação entre os alunos fora da sala de aula ou mesmo dentro da sala de aula tende a promover indicadores que influenciam o processo de aprendizagem do aluno.

A sala de aula invertida é uma metodologia ativa que, basicamente, une o ensino tradicional em sala de aula presencial e o ensino a distância, por isso não é comum encontrar na literatura trabalhos que propõem a aplicação unilateral dessa metodologia. Entretanto, devido à pandemia do novo coronavírus e os impedimentos inesperados para o funcionamento de atividades regularmente presencial, surge então a necessidade de adaptação dessa modalidade para um ambiente remoto. É o que propõe os estudos em (Khan \& Abdou, 2020) e (Naw, 2020).

\section{Modelagem da disciplina}

Este trabalho faz parte de um projeto de pesquisa-ação e pesquisa experimental desenvolvido com estudantes de Ciência da Computação de uma universidade federal, com foco principalmente na disciplina de Inteligência Artificial (IA). Esta é uma disciplina obrigatória de 64 horas, com uma ementa bastante abrangente, contendo: Introdução; Resolução de problemas; Conhecimento e raciocínio; Aprendizado; Processamento de linguagem natural e aplicações. Embora seja um curso com forte interesse acadêmico, que serve de base para a formação de futuros profissionais em Ciência de Dados (Waller \& Fawcett, 2013), o curso vinha apresentando taxas de aprovação abaixo da média nos últimos semestres.

Para este estudo, analisamos turmas diferentes de IA (Tabela 1), com pequenas variações na metodologia. As mudanças na metodologia foram graduais para investigar o resultado das diferentes aplicações e propor melhorias com base no feedback dos alunos. Esse processo é o conhecido processo de melhoria contínua (Brown \& Marshall, 2008).

Desistências ocorreram nos cursos, sendo duas desistências no grupo A, duas desistências no grupo B e duas desistências no grupo C. A Tabela 1 é referente ao total de alunos que de fato participaram do estudo.

Tabela 1: Total de alunos que participaram do estudo. Em "2018/2" refere-se ao segundo semestre de 2018. Em "2019/w" refere-se à turma de inverno e 2019/1 refere-se ao primeiro semestre de 2019.

\begin{tabular}{|c|c|c|}
\hline Grupo & Período & Total de estudantes \\
\hline A & $2018 / 2$ & 5 \\
\hline B & $2019 / 1$ & 17 \\
\hline C & $2019 / 1 \mathrm{w}$ & 12 \\
\hline
\end{tabular}

\subsection{Projeto de Ensino}

O projeto de ensino da disciplina de IA foi redesenhado com base nos princípios de PBL e sala de aula invertida. As técnicas mencionadas anteriormente são essenciais porque oferecem aos alunos a oportunidade de trabalhar em problemas práticos, desenvolvendo habilidades importantes para os profissionais de informática. Como a IA é um ramo da computação que cresceu 
significativamente nos últimos anos, tanto tecnologicamente como profissionalmente, o interesse e a demanda pela disciplina aumentaram. O curso apresenta uma boa oportunidade de alinhar o ensino às demandas do mercado, proporcionando aos alunos uma perspectiva profissionalmente diferenciada, além de permitir que eles ingressem no campo da Ciência de Dados.

A Figura 1, ilustra o modelo de sala de aula usado. O modelo foi baseado na taxonomia de Bloom, referenciado em (Adams, 2015).

\section{Taxonomia de Bloom na sala de aula invertida}

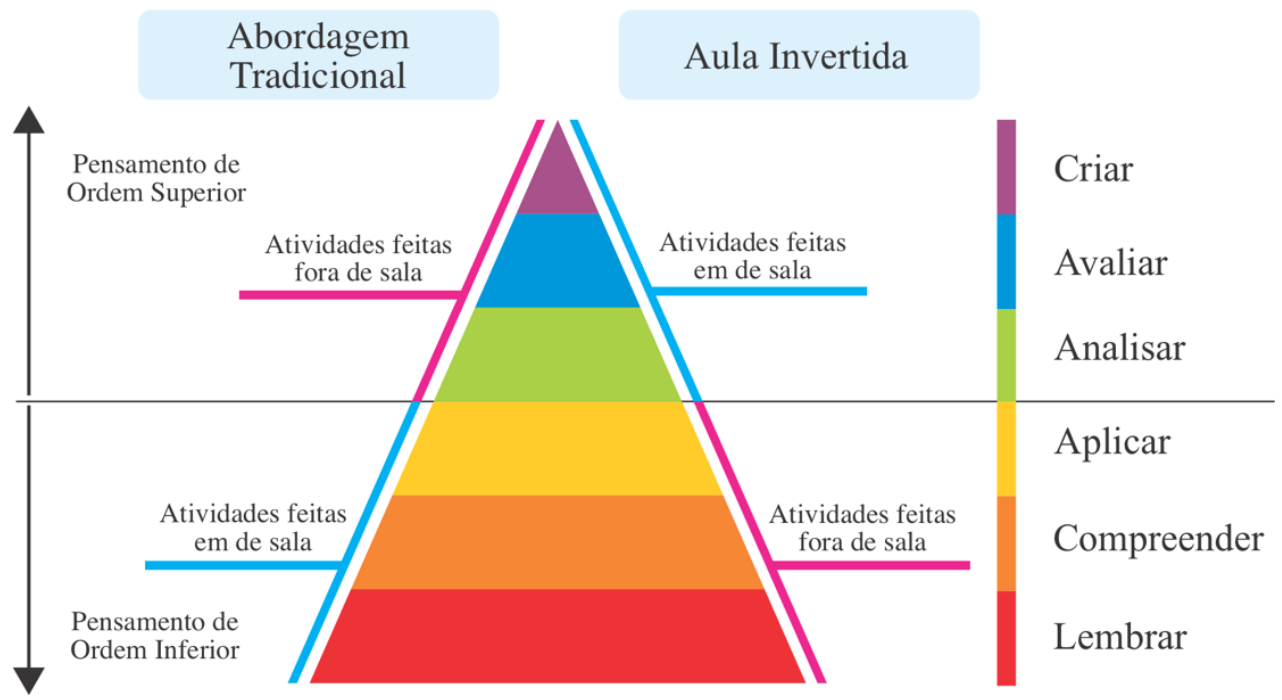

Figura 1: Diagrama de Bloom representativo da mudança de paradigma entre o modelo tradicional de sala de aula e a sala de aula invertida. Fonte: Adaptado de (Munir, Baroutian, Young, \& Carter, 2018).

Entre os desafios do século XXI, atender às novas gerações e a necessidade de uma metodologia de ensino que atualize a sala de aula tradicional e sua metodologia de aulas expositivas e avaliações padronizadas são essenciais. A sala de aula invertida é uma resposta à essa necessidade de mudança e propõe o engajamento do aluno por meio dos seus resultados, levando em consideração o objetivo que o professor busca desenvolver nos alunos.

$\mathrm{O}$ processo de ensino-aprendizagem engloba três áreas: a Cognitiva, a Afetiva e a Psicomotora. A área cognitiva é responsável pela dominação de determinado conhecimento por um indivíduo; A área afetiva é responsável pelo desenvolvimento dos sentimentos e posturas e a área psicomotora está relacionada ao desenvolvimento de habilidades físicas. Para (de Souza Ortiz, 2018) uma vez que a utilização da Taxonomia de Bloom em conjunto com a gamification potencializa o processo de ensino-aprendizagem e a cooperação nos grupos que esses indivíduos estão envolvidos, é possível que o desenvolvimento intencional dessas áreas proporciona uma experiência completa de aprendizagem que promove a autonomia, o domínio e o propósito desse indivíduo.

A base da sala de aula invertida é a Taxonomia de Bloom. Os primeiros questionamentos de B.S Bloom, ainda em 1956, foram sobre os níveis de compreensão de diferentes estudantes sobre determinado conteúdo. Logo, a hipótese de que o ambiente fora da sala de aula fosse influenciado pelo desempenho dos alunos foi descartada. Também foi constatado que o desempenho estava relacionado à variedade dos perfis desses estudantes (Bloom et al., 1971). Constantemente revisitada e adaptada, a Taxonomia de Bloom é a maior referência para um planejamento de aula assertivo e por determinar diretrizes contextual, regional, nacional e individual. Além de oferecer base para instrumentos de avaliação, ela estimula educadores a guiarem os alunos na busca do desenvolvimento de competências e habilidades (Ferraz \& Belhot, 2010). 
A Taxonomia de Bloom Digital é uma adequação que busca auxiliar o professor com o uso das TICs $^{7}$ e verbos ${ }^{8}$ adequados para o planejamento de aula em Ambientes Virtuais de Aprendizagem. A taxonomia é representada por uma pirâmide composta por objetivos educacionais cognitivos hierarquicamente organizados, de um nível de conhecimento menos complexo para o mais complexo (Galhardi \& Azevedo, 2013). Essa estrutura é essencial para que o professor alinhe suas expectativas e ações. No planejamento da sala de aula invertida, ao utilizar o tempo fora da sala de aula para aquisição de conhecimento teórico (base da pirâmide) e valorizar o tempo em conjunto para criação, a sala de aula invertida inova sem abandonar o conhecimento primordial. A seguir, são apresentadas e conceituadas cada categoria da pirâmide.

Nível Lembrar: significa recuperar, reconhecer e lembrar do conhecimento a longo prazo. Os verbos que podem ser utilizados para alcançar esses objetivos são: descrever, listar, conectar, destacar e memorizar. Nas abordagens I, II, III e IV descritas a seguir, os Estudos Dirigidos (EDs) foram utilizados na primeira fase com o objetivo de que os alunos memorizassem os conhecimentos fundamentais da disciplina de IA. Dessa forma, o aluno desenvolve autonomia e base de conhecimento para as próximas fases do estudo.

Nível Entender: significa seguir ou utilizar um conhecimento por meio da execução. Para o discente alcançar esses objetivos, os verbos utilizados podem ser: comparar, escrever e demonstrar. Para isto, nas abordagens III e IV, foi utilizado o processo de trabalho em grupo para elaboração do modelo. Neste cenário, os alunos discutem, criam e comparam ideias a respeito da melhor solução a ser adotada.

Nível Aplicar: significa seguir ou utilizar um procedimento por meio da execução. Para alcançar esses objetivos, os verbos mais adequados para o planejamento de aula são: ilustrar; editar e carregar. Nas abordagens I, II, III e IV, os alunos precisaram aplicar o conhecimento adquirido durante o estudo teórico a um problema sugerido pelo professor.

Nível Avaliar: significa efetuar um julgamento com base em critério e padrão. Os verbos mais utilizados são: criticar, convencer, moderar, validar, tirar conclusões e refletir. Nas abordagens III e IV, a proposta de avaliação utiliza o gamification para estimular os alunos a produzirem melhores resultados.

Nível Criar: significa reunir e reorganizar elementos por meio da criação e planejamento. Os verbos mais utilizados para esses objetivos são: colaborar, designar, publicar, desempenhar papéis. Nas abordagens II, III e IV, a formação de grupos com perfis diferentes foi proposital e teve por objetivo estimular a colaboração de alunos com habilidades diferentes para a resolução de um mesmo problema.

A proposta de metodologia de ensino aqui descrita, utiliza o conceito de sala de aula invertida, PBL e gamification. A seguir, serão apresentadas as três abordagens utilizadas, que foram aplicadas em diferentes turmas e semestres. A disciplina IA é oferecida para alunos que já cursaram disciplinas como Lógica Matemática, Estrutura de Dados e Programação de Computadores. A carga horária da disciplina é de 64 horas, sendo 48 horas dedicadas à parte teórica e 16 horas para atividades práticas. Em sala, os alunos têm a oportunidade de aplicar o conteúdo que estudaram na parte teórica. Uma vez que o aluno conhece os principais conceitos relacionados a um tópico específico em estudo, ele pode trabalhar em sala de aula com um problema real, usandoas técnicas de IA.

Neste projeto, os alunos foram incentivados a usar seus próprios laptops nas aulas. Laptops foram fornecidos para aqueles que não tinham laptops próprios ou não puderam levá-los para a

\footnotetext{
${ }^{7}$ Tecnologias da Informação e Comunicação

${ }^{8}$ Exemplos são dados a seguir no texto.
} 
aula.

$\mathrm{Na}$ disciplina foi usada a linguagem de programação $P y t_{h o n^{9}}$, junto com o ambiente do Google Colaboratory ${ }^{10}$. A plataforma Google Colaboratory Cloud emula ambientes virtuais para a linguagem Python, fornecendo armazenamento, memória e Graphics Processing Unit (GPU) para o processamento do modelos de IA. Um professor e um monitor assistente acompanharam as aulas no laboratório. O professor foi responsável pelo planejamento de atividades práticas que envolviam problemas, e o monitor observou e ajudou o professor em sala. $\mathrm{O}$ ambiente virtual do $M_{o o d l e}{ }^{11}$ foi utilizado como repositório de conteúdo, instrumento de comunicação entre alunos e professor e entre os próprios alunos e como ferramenta de avaliação. Além disto, o projeto foi desenvolvido em três abordagens que configuram uma evolução da metodologia ao longo de sua implementação.

\subsection{Abordagem I}

A primeira abordagem está representada na Figura 2. O estágio I, "Aulas Expositivas", foi desenvolvido por meio de aulas expositivas tradicionais com o objetivo de contextualizar os alunos no curso. Na primeira aula, foi apresentada a metodologia da disciplina para os alunos. Nas aulas seguintes, foi apresentada uma visão geral da IA, as ferramentas a serem utilizadas e os princípios básicos para a resolução de problemas. Neste estágio, o professor atuou como agente principal explicando a metodologia e apresentado as ferramentas necessárias para o andamento do curso. Além disso, mais três aulas foram ministradas na forma tradicional, objetivando treinar os alunos no pré-processamento da base de dados a ser utilizada no curso.

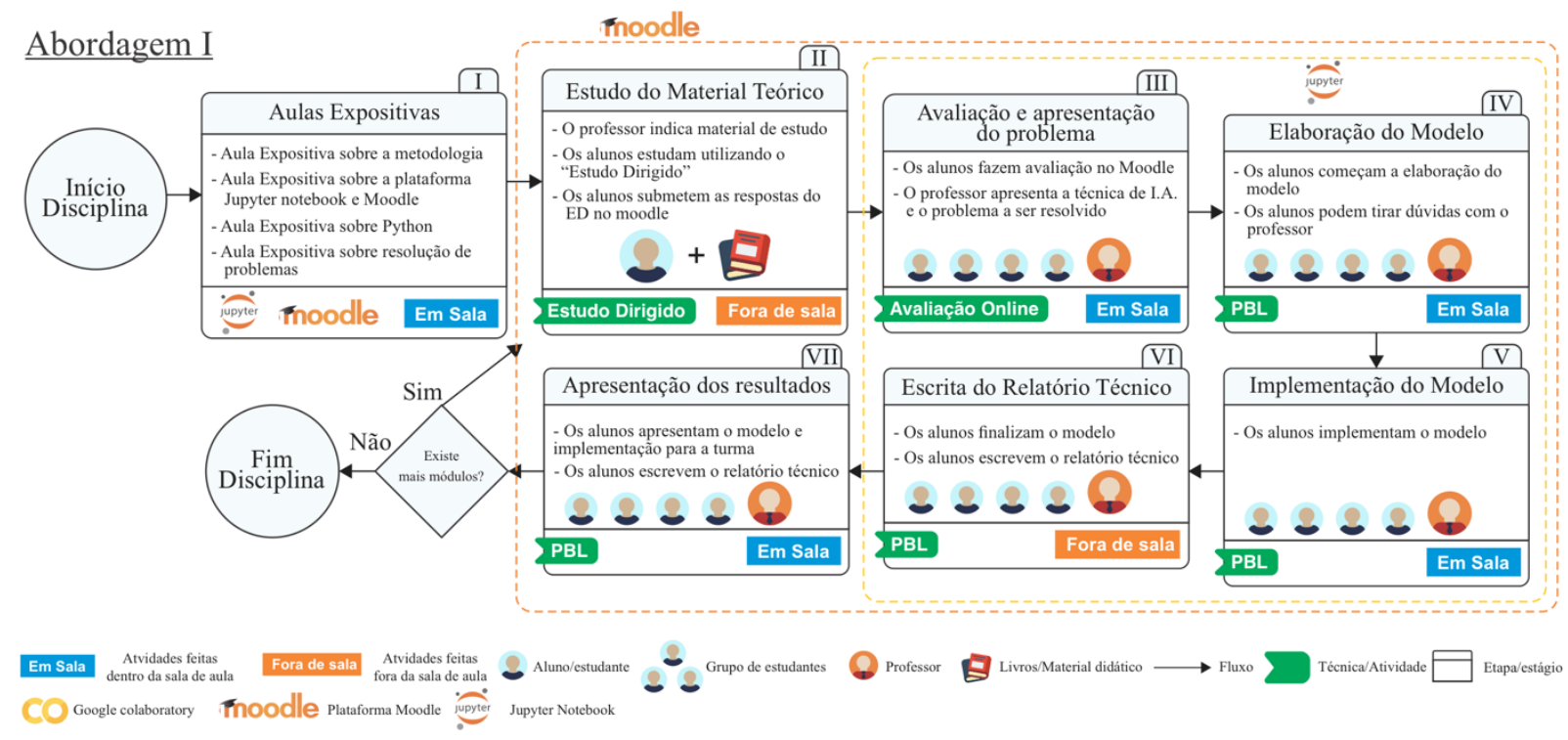

Figura 2: Meta-arquitetura da primeira abordagem. Fonte: Autoria própria.

$\mathrm{Na}$ abordagem I, foram utilizados os conceitos de sala de aula invertida e aprendizado baseado em projetos. O Moodle e o Jupyter Notebook foram utilizados como ferramentas de suporte.

No estágio II, "Estudo do Material Teórico", o professor disponibilizou o material das aulas na plataforma Moodle, juntamente com o cronograma geral da disciplina. Os alunos deveriam estudar o material fora de sala de aula. Para tentar garantir que os alunos tivessem o conhecimento básico necessário para as aulas presenciais, eles foram orientados em seus estudos fora da sala de

\footnotetext{
${ }^{9}$ https://www.Python.org/

${ }^{10} \mathrm{https} / / /$ colab.research.Google.com/notebooks/welcome.ipynb

${ }^{11}$ https://Moodle.org/
} 
aula por meio de um ED. Este ED, foi constituído de questionários elaborados pelo professor e deveriam ser respondidos após o estudo do material teórico (livro didático, literatura complementar, entre outros). Dessa forma, o estudo foi conduzido de forma que os alunos entendessem quais elementos conceituais eles precisavam dominar antes de iniciarem o trabalho com as atividades práticas. Nesta etapa, o estudo ED (as respostas do questionário) deveria ser submetido, por meio da plataforma Moodle, para revisão e avaliação do professor.

No estágio III, "Avaliação e apresentação do problema", os alunos fizeram uma avaliação online. O professor introduziu a técnica de IA a ser estudada, e propôs um problema a ser resolvido. A seguir, apresentou um exemplo de modelo para a resolução do problema proposto, com base nesta técnica. Em seguida, o professor orientou os alunos para que criassem seus próprios modelos para resolver o problema proposto.

No estágio IV, "Elaboração do Modelo", os alunos deveriam construir uma representação abstrata do problema (modelo) a ser implementado no estágio seguinte. Neste estágio e no anterior, os alunos foram estimulados a discutirem seus modelos com o professor.

No estágio V, "Implementação do Modelo", os alunos deveriam construir umaimplementação computacional, em linguagem Python, dos seus modelos abstratos. Nesta etapa, foi usada a ferramenta Jupyter Notebook para auxiliar no processo de implementação dos modelos.

No estágio VI, "Escrita do Relatório Técnico", os alunos deveriam redigir um relatório técnico reportando as atividades desenvolvidas, desde a elaboração do modelo até a produção e avaliação dos resultados finais obtidos.

No estágio VII, "Apresentação dos Resultados", os alunos foram convidados a apresentar seus trabalhos. Cada aluno teve até 10 minutos para apresentar seus resultados. Foram necessárias duas aulas para apresentação dos trabalhos de todos os alunos da turma.

Após finalizadas as apresentações, o ciclo do processo se reiniciou, com retorno ao estágio II do diagrama, para o estudo da próxima técnica de IA. Isso se repetiu até que não houvessem mais técnicas de IA a serem estudadas. Ao final da disciplina, os estudantes preencheram um formulário com 12 questões a respeito da metodologia adotada durante o curso. Tal formulário foi utilizado para identificar as críticas e sugestões dos alunos a respeito da metodologia utilizada e também para contribuir com um processo de melhoria contínua de acordo com o feedback dos estudantes.

\subsection{Abordagem II}

Nesta abordagem, foram colhidas as informações do feedback dos alunos da abordagem I, como também identificados pontos críticos que dificultavam o sucesso da metodologia, o que resultou na implementação de novas técnicas que serão descritas nesta seção.

Constatou-se que boa parte dos estudantes tinham bastante dificuldade com programação. Pensando nisso, optou-se por utilizar técnicas de trabalho em grupo nesta fase. Passou-se a adotar o ambiente compartilhado, em nuvem, da Google, o Google Colaboratory (colab) que, propicia um completo suporte de desenvolvimento colaborativo online, em linguagem Python. Assim, no estágio I, as aulas iniciais foram ministradas no mesmo padrão da abordagem I, com 6 aulas expositivas sobre a metodologia, visão geral da IA, ferramentas e resoluções de problemas.

No estágio II, foram introduzidos materiais em vídeos, além dos livros e artigos. Os vídeos foram selecionados na internet e apresentavam conceitos básicos necessários para a aula. Conforme observado em (De Grazia, Falconer, Nicodemus, \& Medlin, 2012), os alunos que têm a opção de vídeoaulas tendem a vir para a aula mais bem preparados do que os alunos que têm somente a opção de ler textos. A oferta dessa opção é importante porque, embora o aprendizado seja significativo para o conteúdo apresentado textualmente, os alunos raramente concluem as 
leituras conforme estudo de (Sappington, Kinsey, \& Munsayac, 2002). Os EDs foram mantidos nesta etapa.

No estágio III, a turma foi dividida em grupos de três estudantes. O objetivo, além de incentivar o trabalho colaborativo na resolução dos problemas, foi de amenizar o fato de alguns estudantes não dominarem técnicas de programação e linguagem Python. Além disto, um formulário inicial foi introduzido no estágio I para identificar quais alunos tinham melhores habilidades como programadores. Isto foi necessário para podermos distribuir os grupos de maneira que cada grupo fosse composto por pelo menos um membro com boas habilidades de programador. Foi exigido que os membros dos grupos criassem um projeto, organizado na plataforma Trello, para que os grupos pudessem gerenciar de melhor forma as atividades, e também para que o professor pudesse auxiliar o líder do grupo a coordenar sua a equipe.

No estágio IV, os grupos elaboraram coletivamente o modelo computacional, com a ajuda do professor, em sala.

No estágio V, os alunos implementaram coletivamente o modelo computacional para solução do problema.

No estágio VI, os alunos finalizaram a implementação e redigiram o relatório técnico a ser apresentado na próxima fase. No estágio VII, o líder do grupo apresentou os resultados obtidos para a turma em sala. Houve uma melhora significativa no desempenho dos grupos e das propostas para solução dos problemas. Ao final do curso, os alunos deram feedbacks através de um formulário, apontando o que foi efetivo ou não durante o curso, sob os seus pontos de vista.

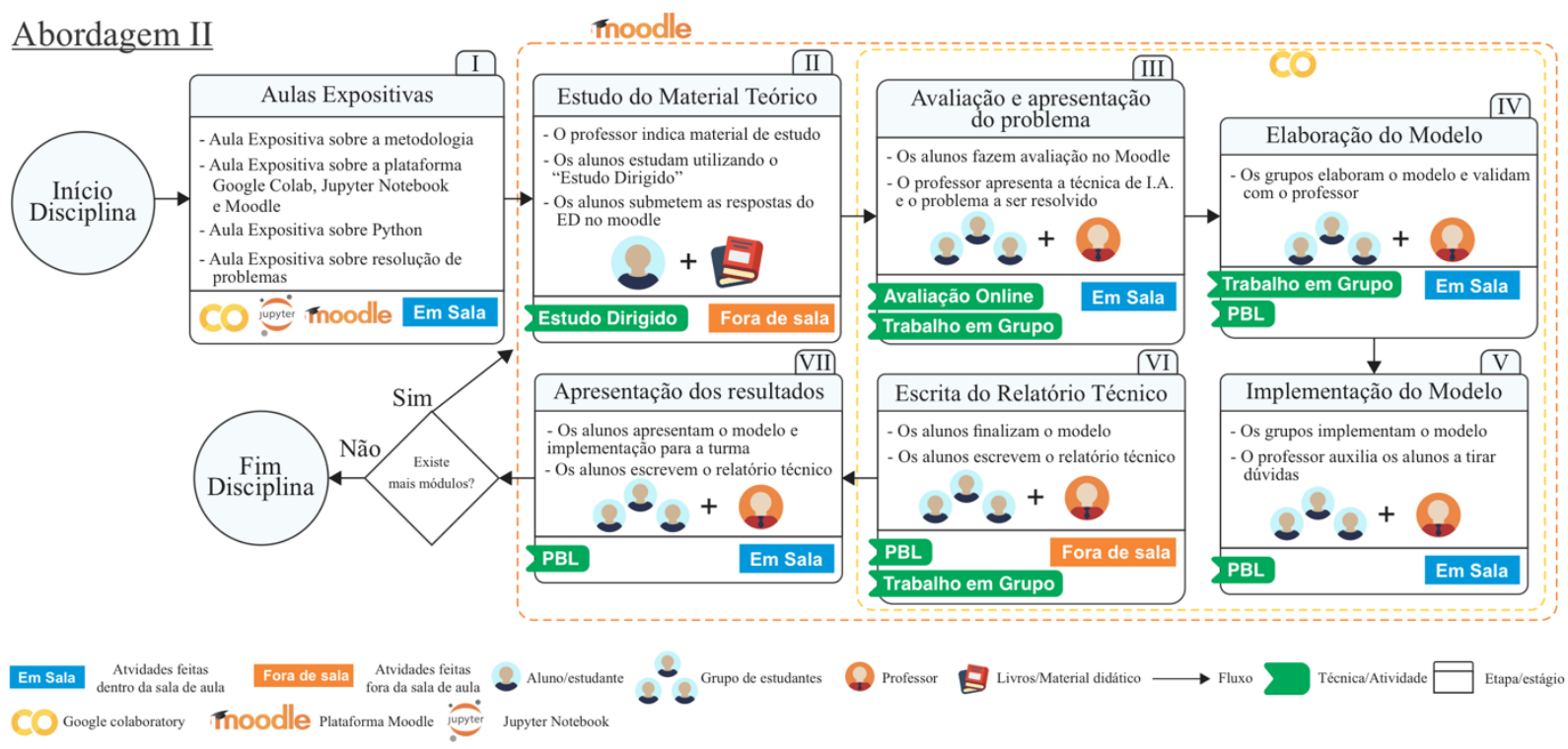

Figure 3: Meta-arquitetura da segunda abordagem. Fonte:Autoria própria.

\subsection{Abordagem III}

Nesta abordagem, novamente utilizou-se os feedbacks da turma anterior para identificar pontos de melhorias e falhas da metodologia. Nesta fase, foram implementadas novas técnicas e conceitos que serão descritos logo em seguida.

Em grupos compostos por três estudantes, cada membro recebeu um papel a desempenhar. Um dos alunos foi designado como "Gerente de Projeto". Ele era responsável por gerenciar todas as atividades do grupo e também por apresentar os resultados produzidos pelo grupo em cada módulo (correspondente a um ciclo de aplicação da metodologia, com o estudo de uma técnica de IA). Além do gerente, havia dois outros papéis, o "Programador" e o "Analista de Dados". O 
programador foi o responsável direto pela implementação computacional do modelo desenvolvido pelo grupo. O analista de dados foi responsável por analisar os dados fornecidos, trazendo informações úteis ao grupo sobre como os dados se comportavam, por meio de visualizações e gráficos que seriam utilizados pelo gerente nas apresentações de resultados. Ele foi também o responsável por construir os conjuntos de exemplos, a partir da base de dados, a serem usados no treinamento supervisionado dos modelos.

No estágio I, da abordagem III, conforme representado na Figura 4, foi introduzido o formulário de identificação de perfis para que cada grupo obtivesse ao menos um membro com habilidades de programador. O total de aulas seguiu o mesmo padrão de seis (6) aulas expositivas sobre a metodologia, visão geral da IA, apresentação das ferramentas e introdução à resolução de problemas. Esta apresentou bons resultados (feedbacks positivos). Logo, não houve modificações neste processo.

No estágio II, não houve modificações, o professor apresentou o material teórico e os EDs para que o aluno pudesse se preparar para as atividades em sala.

No estágio III, optou-se por uma abordagem diferente. Nesta etapa, técnicas de gamification foram introduzidas na metodologia. Nas abordagens I e II, os alunos precisavam submeter os EDs no Moodle para que o professor fizesse a avaliação. Nesta fase, optou-se por um quiz (jogo de perguntas e respostas), utilizando as questões dos EDs. Como recompensa, o grupo que mais acertou questões receberia um acréscimo de até $10 \%$ na média final.

No estágio IV, o gamification foi introduzido aos alunos através de cargos que especificavam as tarefas que cada membro deveria desempenhar no grupo. A ideia desta etapa é reforçar a característica lúdica dos jogos em uma tentativa de simular um ambiente real de trabalho para os estudantes.

No estágio $\mathrm{V}$, os alunos com papéis de programadores efetuaram a codificação do modelo desenvolvido pelo seu grupo. O gerente coordenou o processo e o analista de dados trabalhou em conjunto com o programador para gerar visualizações e insights sobre os dados.

No estágio VI, tanto o programador quanto o analista de dados, entregaram o modelo e os resultados da análise para o gerente montar sua apresentação. O gerente foi o responsável pela apresentação e escrita do relatório técnico.

No estágio VII, o gerente de cada projeto apresentou a solução desenvolvida pelo seu grupo para os demais grupos em sala. 


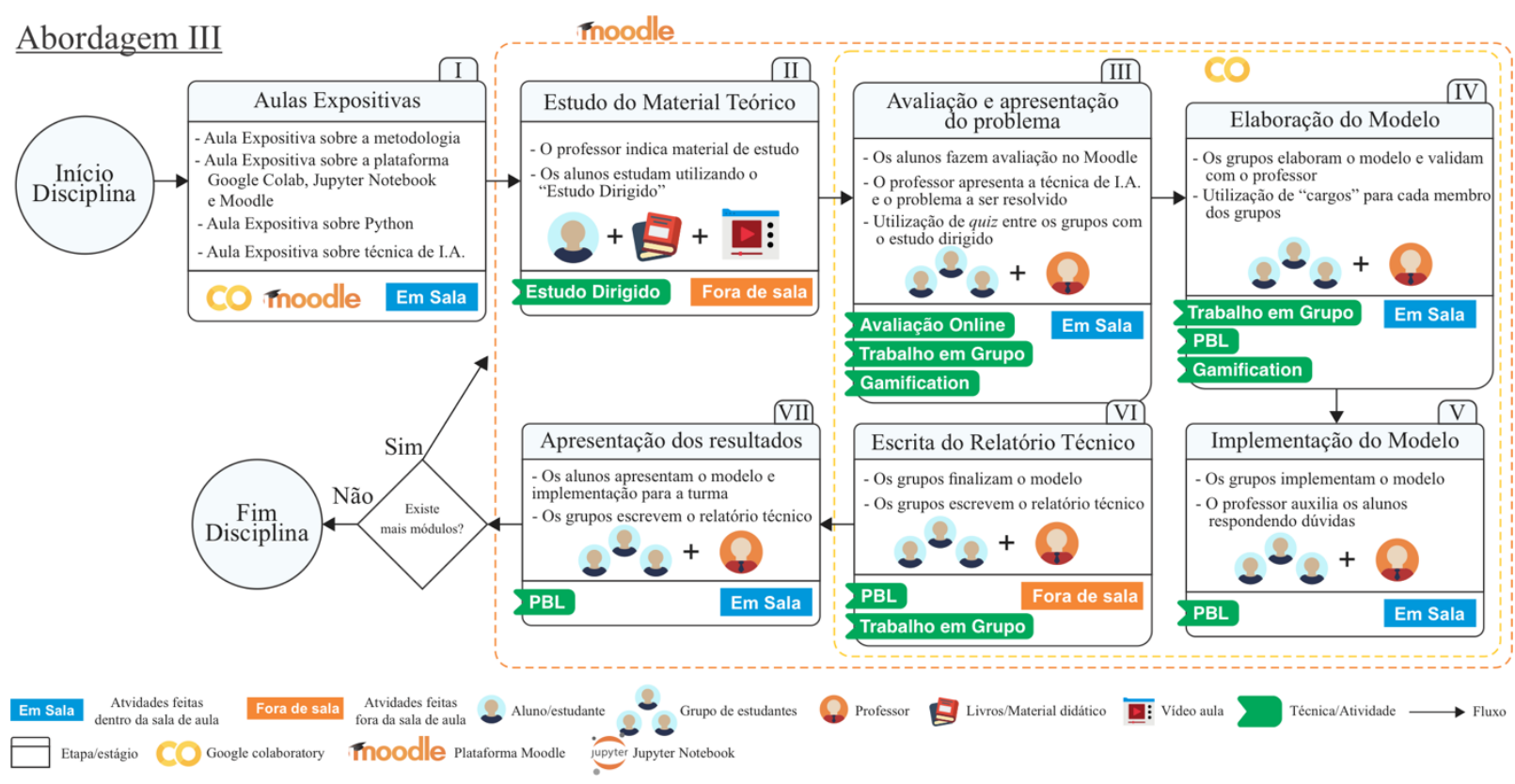

Figura 4: Meta-arquitetura da terceira abordagem. Fonte: Autoria própria.

\subsection{Abordagem IV, evolução da sala de aula invertida para aulas remotas}

O modelo apresentado na abordagem III foi modificado de forma a ajustar-se às necessidades de aulas remotas. Assim, a metodologia foi ajustada, considerando o modelo de sala de aula invertida, como também a combinação de técnicas e ferramentas capazes de dar suporte a um ambiente de ensino totalmente remoto (Figura 5).

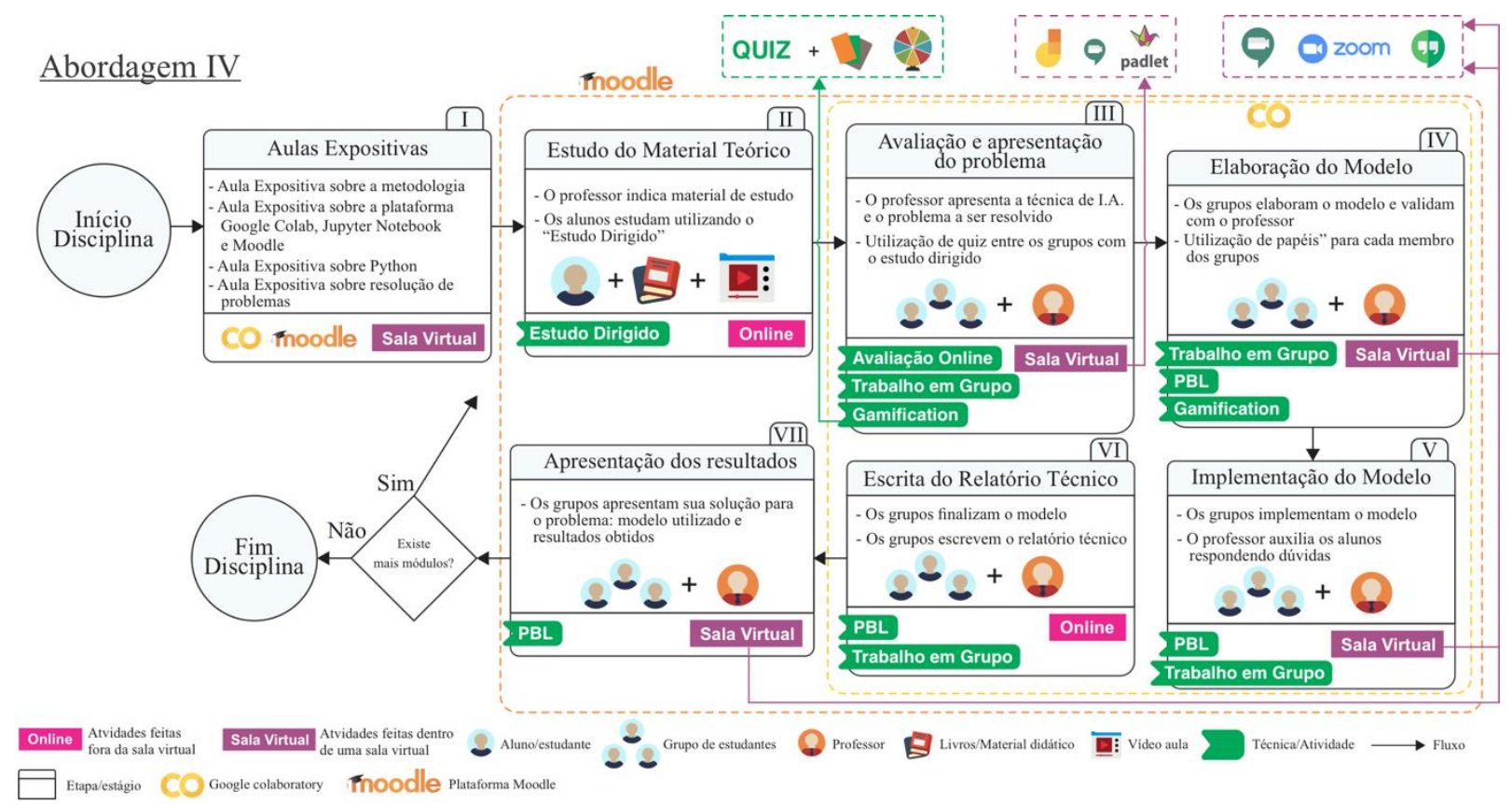

Figura 5: Meta-arquitetura de implantação da metodologia de sala de aula invertida para aulas remotas. Fonte:Autoria própria.

No estágio I, as aulas expositivas ocorrem por meio de sala virtual onde o professor conduz a aula com os alunos em um ambiente totalmente online e virtual. Dentre os softwares disponíveis, optou-se por utilizar o Google Meet ${ }^{12}$ que fornece salas virtuais que podem ser adaptadas para aulas 
remotas. No entanto, pode-se utilizar outras ferramentas como Zoom $^{13}$ e Google Hangout ${ }^{14}$ que também oferecem serviços semelhantes. As seis (6) aulas expositivas e o formulário de identificação de perfil do aluno também são utilizados neste estágio.

No estágio II, os alunos devem utilizar os EDs para guiarem seus estudos teóricos. Nesta etapa, mantivemos os livros, artigos e vídeos que funcionarambem na abordagem III.

No estágio III, o professor utiliza a sala virtual do Google Meet para se conectar com toda a turma em um ambiente de sala virtual. Neste estágio, são utilizadas algumas técnicas de gamification como o quiz que já era utilizado na abordagem III, porém foi preciso adaptá-lo para um ambiente totalmente remoto. Dentre as soluções encontradas, optou-se por utilizar o Google Jamboard, que é uma plataforma na qual é possível adaptar um jogo de cartas (opção (a), da Figura 6).

No quiz, o aluno escolhe uma carta que ele deseja virar, após escolha, o professor vira a carta e o aluno precisa responder à questão que está no verso da carta. Caso o aluno, que neste momento representa um grupo, acerte a resposta, é acrescido um ponto ao grupo. Esta técnica trás aspectos interessantes sobre gamification, mais especificamente sobre mecânica de games, como por exemplo, a sorte, que dá ao estudante a expectativa pelo inesperado, pelo aleatório, pela sorte. Outro fator é o desafio, as cartas poderiam ter pesos, e o aluno saberia que pesos maiores significam recompensas maiores, porém questões mais difíceis de serem respondidas gerando também a sensação de recompensa. Há também o elemento da cooperação e competição, uma vez que o aluno representa um determinado grupo quando está respondendo as questões. E por último, o estado de vitória, caso um grupo acerte mais cartas que os demais, será gerado um sentimento de vitória durante a atividade. Todas estas mecânicas são baseadas no trabalho de (Werbach \& Hunter, 2015).

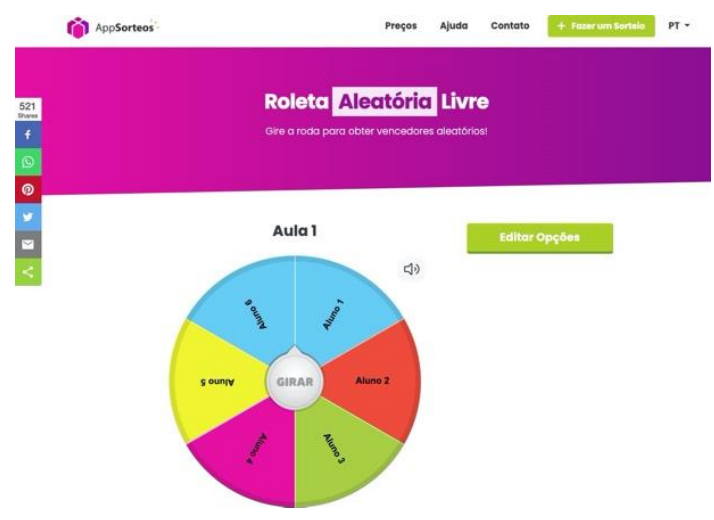

a) Jogo de cartas adaptado na plataforma Google Jamboard.

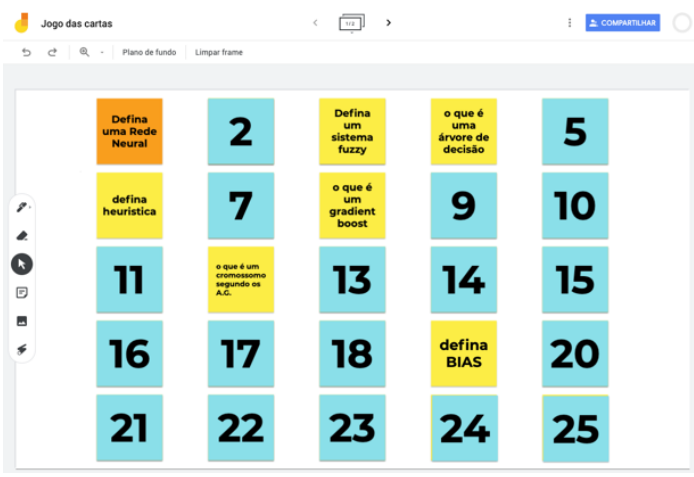

b) Roleta personalizável do site app-sorteios

Figure 6: técnicas de games para quiz de perguntas. Fonte: Adaptado de Google Jamboard e site app-sorteis.

Outra possibilidade é o uso da aleatoriedade, como no jogo da roleta. O professor cria uma roleta com os nomes dos alunos ou grupos. Após isto, escolhe uma questão a ser respondida do ED e gira a roleta sorteando um aluno para responder. Os pontos são contabilizados de forma individual ou em grupo. Neste processo, o sentimento de aleatoriedade é bem mais presente do que no jogo das cartas. Por exemplo, a ferramenta app-sorteios $^{15}$ (opção (b), na Figura 6), pode ser utilizada.

No estágio IV, os alunos devem trabalhar colaborativamente na elaboração do modelo em salas virtuais ou grupos online. Neste estágio, os alunos podem se reunir em salas do Google Meet,

\footnotetext{
${ }^{13}$ https://zoom.us/

${ }^{14}$ https://hangouts.Google.com/

${ }^{15} \mathrm{https}$ ://app-sorteios.com/pt/apps/girar-roleta-aleatoria
} 
Hangout, Zoom, chamada de vídeo por WhatsApp, Telegram. Nesta etapa, é importante também que, caso os alunos desejem utilizar algum software de quadro virtual, ferramentas como Google Jamboard, padlet e Trello podem ser utilizadas para organizar e compartilhar ideias entre os membros do grupo. O Trello é uma ferramenta muito interessante para o gerente do grupo poder organizar as tarefas a serem cumpridas por ele e os membros do grupo.

Além disso, nesta abordagem o professor sugere que os grupos dividam suas atividades de acordo com o papel de cada estudante no grupo, diferentemente da abordagem III em que os papéis foram obrigatórios aos grupos. A ideia desta proposta é dar aos estudantes a possibilidade de construírem seus cargos e atribuições de acordo com a habilidade de cada membro do grupo.

No estágio $\mathrm{V}$, os alunos podem continuar utilizando os canais de comunicação citados no estágio IV. Devido ao sucesso da utilização da plataforma Google colab, a codificação pode ser mantida neste ambiente, incentivando a colaboração e visualização da implementação do modelo computacional pelos demais membros do grupo a fim de completarem a codificação do modelo.

No estágio VI, os grupos continuam usando os canais de comunicação e efetuam a escrita do relatório. Para isto, foi sugerido, a plataforma Overleaf, para escrita do relatório técnico, utilizando a linguagem LaTex.

No estágio VII, os grupos efetuam a apresentação e entrega do documento com a solução para o problema, utilizando a técnica de IA do módulo atual. A apresentação pode ser feita nos canais de comunicação citados no estágio III, podendo o professor gerenciar a ordem de apresentação.

A utilização de gamification e técnicas de games foram reforçadas nesta abordagem IV como uma tentativa de estimular o interesse e a atenção do aluno durante as aulas remotas. Foram selecionados softwares com maior afinidade com a proposta da metodologia, porém, sugestões de alternativas também foram indicadas para futuras implementações em contextos diferentes. A Tabela 2, a seguir, retrata as técnicas e tecnologias utilizadas nas diferentes abordagens.

Tabela 2: Tecnologias e ferramentas utilizadas nas abordagens. A sigla SGA é referente a "Sistemas Gerenciadores de Aprendizagem".

\begin{tabular}{|c|c|c|c|c|}
\hline Abordagem & Técnicas & Material didático & SGA & $\begin{array}{c}\text { Tecnologias } \\
\text { para aulas }\end{array}$ \\
\hline I & $\begin{array}{l}\text { - PBL } \\
\text { - Sala de aula invertida }\end{array}$ & $\begin{array}{l}\text { - Livros } \\
\text { - Artigos } \\
\text { - Estudo Dirigido }\end{array}$ & - Moodle & - Jupyter Notebook \\
\hline II & $\begin{array}{l}\text { - PBL } \\
\text { - Sala de aula invertida } \\
\text { - Trabalho em grupo }\end{array}$ & $\begin{array}{l}\text { - Livros } \\
\text { - Artigos } \\
\text { - Estudo Dirigido } \\
\text { - Vídeos }\end{array}$ & - Moodle & $\begin{array}{l}\text { - Jupyter Notebook } \\
\text { - Google Colab } \\
\text { - Trello } \\
\text { - Overleaf }\end{array}$ \\
\hline III & $\begin{array}{l}\text { - PBL } \\
\text { - Sala de aula invertida } \\
\text { - Trabalho em grupo } \\
\text { - Gamification }\end{array}$ & $\begin{array}{l}\text { - Livros } \\
\text { - Artigos } \\
\text { - Estudo Dirigido } \\
\text { - Vídeos }\end{array}$ & - Moodle & $\begin{array}{l}\text { - Jupyter Notebook } \\
\text { - Google Colab } \\
\text { - Overleaf }\end{array}$ \\
\hline IV & $\begin{array}{l}\text { - PBL } \\
\text { - Sala de aula invertida } \\
\text { - Trabalho em grupo } \\
\text { - Gamification }\end{array}$ & $\begin{array}{l}\text { - Livros } \\
\text { - Artigos } \\
\text { - Estudo Dirigido } \\
\text { - Vídeos }\end{array}$ & - Moodle & $\begin{array}{l}\text { - Jupyter Notebook } \\
\text { - Google Colab } \\
\text { - Overleaf } \\
\text { - Meet } \\
\text { - Google Jamboard } \\
\text { - App-sorteios(roleta) }\end{array}$ \\
\hline
\end{tabular}




\section{Resultados Preliminares}

Os resultados apresentados nesta seção dizem respeito às abordagens I, II e III. As informações levantadas são analisadas tanto do ponto de vista qualitativo, que observou o comportamento de cada aluno, quanto do ponto de vista quantitativo, que mediu os resultados dos EDs, das avaliações em classe, dos relatórios produzidos e das implementações práticas. A análise destes resultados se faz necessária para entender o processo de evolução das abordagens até a elaboração da metodologia de sala de aula invertida para aulas remotas, uma vez que, aproximadamente $30 \%$ das atividades desenvolvidas nas abordagens I, II e III eram feitas fora de sala ou remotamente. $\mathrm{Na}$ abordagem IV , 100\% das atividades devem ser feitas remotamente. Na Figura 7, em (a), são descritas as métricas de avaliação das três turmas estudadas. Em (b) é representado como se fez necessária a migração, em alguns estágios da metodologia, do modelo híbrido de sala de aula no qual ocorriam atividades dentro e fora de sala de aula para uma abordagem totalmente remota.

a)

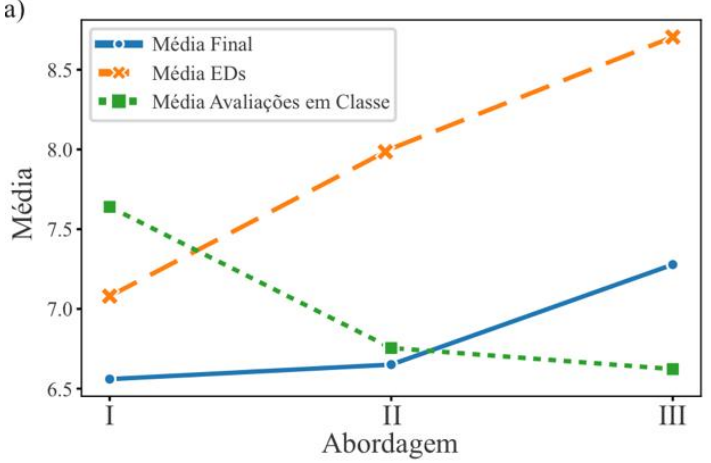

b)

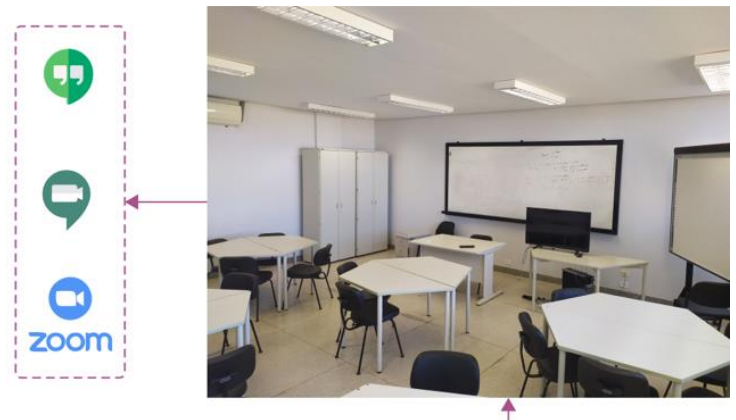

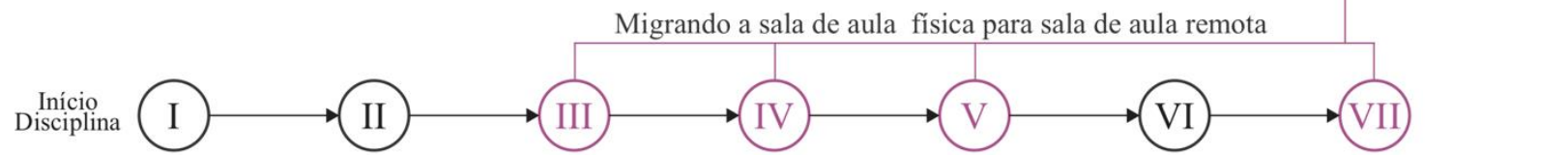

(1) Aulas Expositivas

(II) Estudo do Material Teórico

III) Avaliação e apresentação

(IV) Elaboração do Modelo

(V) Apresentação dos resultados

(VI) Escrita do Relatório Técnico

(VIII) Implementação do Modelo

Figura 7: Em (a) Representação das médias totais obtidas de estudos dirigidos (média EDs), média total do curso (média final) e avaliação em sala de aula (média avaliação em classe). Em (b) migração da sala de aula física para remota. Fonte:Autoria própria.

$\mathrm{Na}$ abordagem III, os alunos obtiveram médias mais altas. Na abordagem I, a média total foi de 6.56, enquanto a abordagem II teve uma média geral de 6.65 e, na abordagem III, a média geral da classe foi de 7.28. As abordagens I e II apresentaram as maiores discrepâncias de notas dos EDs e na média total. As informações das médias, desvio padrão, mínimo, máximo, primeiro, segundo e terceiro quartis podem ser observados na Tabela 3. 
Tabela 3: Tabela referente à análise descritiva das atividades avaliativas. $\sigma$ indica o desvio padrão, e $Q_{1}, Q_{2}$ e $Q_{3}$ representam, respectivamente, o primeiro, segundo e terceiro quartis, $n$ indica o total das amostras e $M$ indica a média.

\begin{tabular}{|c|l|c|c|c|c|c|c|c|c|}
\hline Abordagem & \multicolumn{1}{|c|}{ Avaliação } & $\boldsymbol{n}$ & $\boldsymbol{M}$ & $\boldsymbol{\sigma}$ & Min. & $\boldsymbol{Q}_{\mathbf{1}}$ & $\boldsymbol{Q}_{\mathbf{2}}$ & $\boldsymbol{Q}_{\mathbf{3}}$ & Max. \\
\hline I & \multirow{2}{*}{ Média Final } & 5 & 6.56 & 1.79 & 5.20 & 5.30 & 5.40 & 7.80 & 9.10 \\
II & 17 & 6.65 & 2.20 & 1.13 & 7.09 & 7.46 & 7.72 & 8.95 \\
III & & 12 & 7.28 & 2.84 & 1.23 & 7.15 & 7.94 & 8.70 & 10.00 \\
\hline I & \multirow{2}{*}{ Estudos EDs } & 5 & 7.08 & 3.43 & 1.00 & 8.00 & 8.40 & 9.00 & 9.00 \\
II & 17 & 8.00 & 2.04 & 2.04 & 7.52 & 8.29 & 9.30 & 10.00 \\
III & & 12 & 8.70 & 2.22 & 2.22 & 8.86 & 9.80 & 9.91 & 10.00 \\
\hline I & \multirow{2}{*}{ Avaliação em sala } & 5 & 7.64 & 1.30 & 5.70 & 6.90 & 8.40 & 8.60 & 8.60 \\
II & 17 & 6.75 & 1.75 & 1.72 & 6.43 & 7.11 & 7.48 & 9.12 \\
III & & 12 & 6.62 & 1.68 & 2.26 & 6.55 & 6.88 & 7.78 & 8.14 \\
\hline
\end{tabular}

Observa-se que as médias foram mais altas na primeira abordagem. Suspeitamos que número de alunos nas abordagens II e III, que foi maior que na abordagem I, pode ter influenciado neste resultado. No caso da avaliação em sala de aula, podemos observar que houve um declínio na abordagem II e um ligeiro aumento na abordagem III. Não está claro o que pode ter causado isso, se o número de alunos na sala de aula pode ter influenciado, ou talvez o perfil dos alunos pode ter impactado diretamente o resultado.

A Figura 8 mostra os resultados do questionário de avaliação da metodologia, aplicado ao final de cada curso. O questionário pode ser consultado no Apêndice 6 deste trabalho. Analisando o questionário de avaliação da disciplina para três turmas, obtivemos os seguintes resultados: aproximadamente $85 \%$ dos alunos responderam que, após cursarem a disciplina, consideravam que "o tema IA os fascinava e os interessava". Quanto à metodologia das aulas invertidas, aproximada- mente $57 \%$ dos alunos responderam que a metodologia é boa ou excelente. Os outros responderam com "tanto faz" e uma minoria não gostou da metodologia. Sobre os EDs, aproximadamente $71 \%$ dos alunos responderam que gostaram de usar um estudo guiado por perguntas para estudar o material teórico. Em relação ao trabalho proposto em sala de aula, aproximadamente $65 \%$ dos alunos responderam que eram excelentes ou bons, aproximadamente $23 \%$ responderam que poderiam ser melhor elaborados. Em relação ao desempenho dos alunos, aproximadamente $57 \%$ dos alunos afirmaram ter dificuldade, mas foram capazes de realizar as atividades, outros afirmaram ter dificuldade em realizar atividades em sala de aula ou consideraram-nas muito difíceis.

Em relação aos vídeos sugeridos para o curso, aproximadamente $66 \%$ dos alunos confirmaram que eram úteis na construção de seus conhecimentos, enquanto os outros alegaram que não tinham tempo para observá-los ou se concentraram nos livros. Além disso, em relação à implementação dos modelos em sala de aula, aproximadamente $32 \%$ dos alunos tiveram dificuldade em usar a linguagem Python, 57\% dos alunos tiveram dificuldade em entender a especificação do problema, $15 \%$ afirmaram que não podiam trabalhar sob pressão, enquanto os outros não tinham dificuldades. Com relação à metodologia aplicada em sala de aula comparada às demais utilizadas em outras disciplinas, aproximadamente $57 \%$ dos alunos acreditam que a metodologia é boa, mas precisa ser aprimorada, aproximadamente $28 \%$ dos alunos acreditam que a metodologia deve ser replicada, os outros responderam com a opção "tanto faz". 


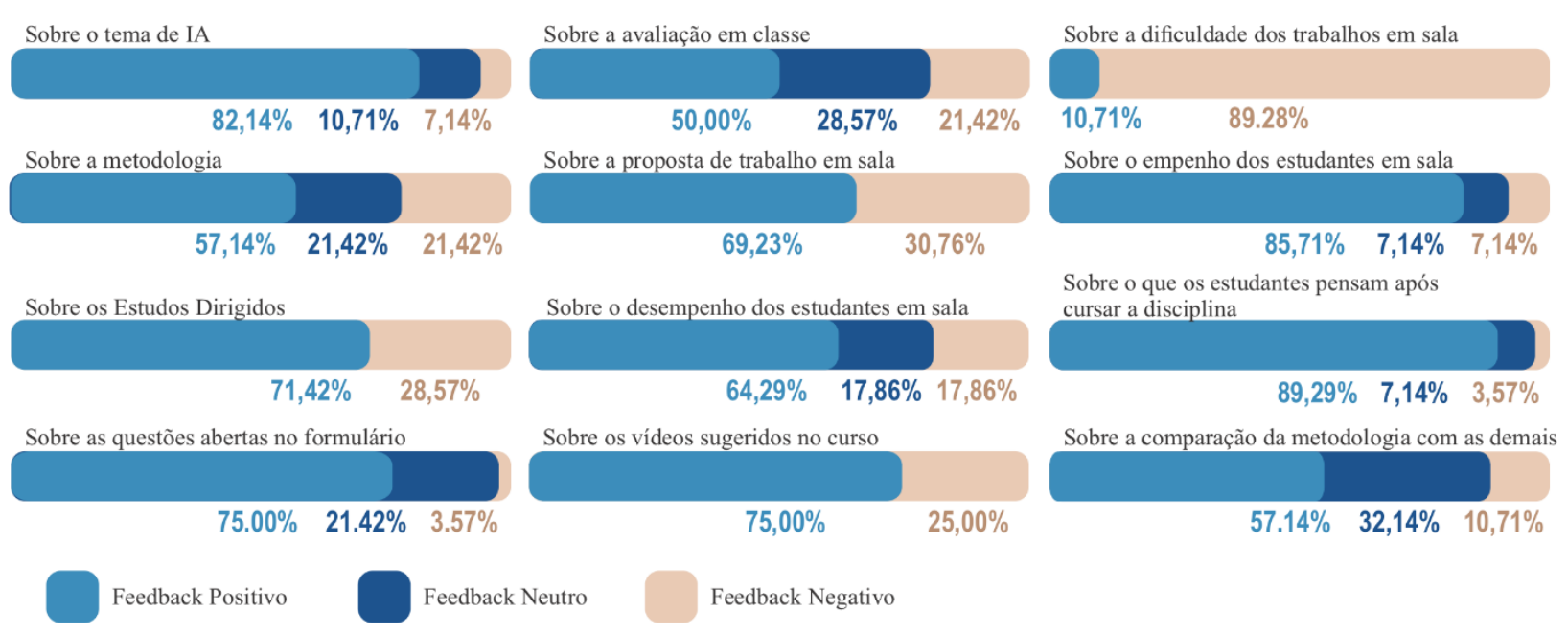

Figure 8: Questionário (Quiz) aplicado aos alunos ao final do curso. O feedback positivo refere-se aos resultados dos alunos que classificaram positivamente as questões ( $\mathrm{a}$ e b). $\mathrm{O}$ feedback negativo e neutro refere-se a respostas neutras ou negativamente classificadas, respectivamente ("c", "d" e "e"). O questionário encontra-se no apêndice deste documento. Fonte: Autoria própria.

Do ponto de vista qualitativo, na abordagem I, percebeu-se que boa parte dos estudantes não possuía experiência anterior com Python, dificultando grande parte do processo de ensino. Como o curso de IA é oferecido a estudantes que já fizeram os cursos CS1 e CS2 (CS1 e CS2 são as disciplinas introdutórias dos cursos de Computação), esperava-se que eles dominassem o conhecimento necessário para desenvolver soluções baseadas em programação e novas linguagens de programação, entretanto, observou-se que uma boa parcela dos estudantes não gostava de programar ou não tinha boas habilidades em programação de computadores.

Além disso, outra dificuldade encontrada durante o processo está relacionada à capacidade de síntese. Isso está associado ao pensamento de primeira ordem pela Taxonomia de Bloom (Adams, 2015). A dificuldade na programação, juntamente com a dificuldade de criar um modelo que represente a solução para um problema, se mostrou bastante evidente na abordagem I. Buscando uma solução para este problema, a metodologia de trabalho em grupo foi de fundamental importância. Durante abordagem II, percebeu-se uma melhora significativa na argumentação e planejamento dos alunos e também nos modelos propostos pelos grupos.

Entretanto, não satisfeito com os resultados, buscou-se melhorar o processo de atividades em grupo para que fosse possível avaliar os estudantes coletivamente e individualmente, haja vista que, alguns estudantes em determinados grupos não colaboravam em sua totalidade para os resultados dos grupos. A abordagem de definição de papéis foi utilizada na abordagem III para criar um ambiente que pudesse simular um time de desenvolvimento (squad) de empresas de tecnologias além de poder trabalhar as "soft skill", habilidades bastante valorizadas no mercado de trabalho. A definição de função/cargo, embora seja uma boa ideia, não funcionou como esperado. No início, o gerente não conseguiu gerenciar os grupos com eficiência e, em alguns casos, o programador assumiu a liderança do grupo porque o líder não tinha as características necessárias para liderar um grupo ou porque o programador poderia explicar melhor a solução proposta. Além disso, o analista muitas vezes trabalhava em paralelo com o programador, desenvolvendo atividades conjuntas e, em outros casos, a omissão do analista era claramente visível. Talvez, uma melhor realocação de membros em grupos, ou melhor distribuição de papéis possa ajudar a amenizar o problema de omissão de atividades de membros no grupo.

Outro fator importante foi o uso de gamification durante o processo. A utilização dos EDs em atividades gamificadas refletiria em uma melhora significativa da participação dos estudantes durante os debates em sala. Percebeu-se que a comunicação, argumentação e demais pensamentos 
de primeira ordem foram utilizados neste processo, maior até na abordagem I. A ideia de recompensa de $10 \%$ a mais na nota pode ter influenciado e motivado os grupos.

O resultado da terceira abordagem nos fez refletir sobre a dedicação dos alunos durante o período de aulas. Nesta abordagem, o curso foi oferecido em uma disciplina de verão, onde os alunos tiveram apenas dois meses para completar a disciplina. O tempo entre o estudo dirigido, a preparação do modelo, implementações, a elaboração do relatório e a apresentação foi curto. Entretanto, contrariando as expectativas, os alunos, por terem dedicação exclusiva, se dedicaram mais. Além de cumprir os prazos, eles foram capazes de entregar o modelo, as implementações e enviar o relatório a tempo, com poucas exceções.

\section{Limitações da Abordagem IV}

Na seção 3.5, é apresentada uma metodologia a partir das experiências adquiridas nas abordagens I, II e III, utilizando conceitos de sala de aula invertida, aprendizado baseado em projeto, trabalho em grupo e gamification. Alguns imprevistos ou gargalos podem ocorrer caso haja uma tentativa de replicação da metodologia em cenários distintos. Por este motivo, serão descritas nesta seção alternativas e limitações da abordagem IV, relativas à evolução da sala de invertida modelo híbrido, com aulas presenciais, para o modelo de sala de aula invertida totalmente remoto. São elas:

1. Condução das aulas: Nas abordagens I, II e III, um auxiliar acompanha o professor na turma durante os períodos em sala. Porém, algumas atividades podem demandar mais atenção e esforço por parte do professor para gerenciar as dinâmicas em sala. É o caso das atividades gamificadas, a exemplo do quiz. É preciso que o professor, além de gerenciar as turmas em sala, também precise monitorar qual aluno acertou qual questão e a qual grupo ele pertence. Os EDs, podem variar suas questões de 10 a trinta 30 dependendo do módulo, dificultando o gerenciamento do processo, caso o professor esteja sem apoio durante as aulas. A falta de um sistema que possa gerenciar esses eventos de contagem de pontos, identificação do aluno e gerenciamento dos turnos de resposta pode acarretar uma sobrecarga durante o processo das atividades gamificadas e por consequência afetando seu resultado.

Outro fator importante, é descrito pela experiência do professor com ferramentas tecnológicas ou softwares. Como o processo acontece totalmente online, espera-se que o professor possua facilidade em agendamento de aulas em ferramentas como Google Agenda, criação de salas remotas em softwares como Google Meet, Zoom ou Google Hangout. Espera-se também que o professor seja capaz de conduzir as atividades gamificadas estando em uma sala virtual e, ao mesmo tempo acessando os softwares de cartas ou de roleta, além de registrar as pontuações dos estudantes.

2. Ausência de um Sistema Gerenciador de Aprendizagem (SGA): Durante as abordagens I, II, III e IV a utilização do Moodle é feita para criação de turmas, disponibilização de conteúdos e cronogramas, fórum de discussão, lançamento de notas entre outros. Porém, alguma instituição de ensino (IE) pode não ter esta ferramenta disponível para dar suporte ao professor durante a utilização da metodologia. Neste caso, pode-se adotar um outro SGA, como Chamilo ${ }^{16}$, Instructure Canvas ${ }^{17}$ ou um outro. Não havendo a possibilidade

\footnotetext{
16 https://chamilo.org/en

${ }^{17} \mathrm{https}: / / \mathrm{www}$. instructure.com/pt-br
} 
de adesão a um SGA, uma opção rápida e prática é a utilização de tabelas e documentos em nuvem para gerenciamento de documentos, notas e turmas.

3. Indisponibilidade de artefatos tecnológicos: Conforme pesquisa feita pelo Centro Regional de Estudos para o Desenvolvimento da Sociedade da Informação ${ }^{18}$ (CETIC.BR), três em cada quatro brasileiros têm acesso à internet. O celular é o principal dispositivo para acessar a Internet, constituindo $99 \%$. A pesquisa ainda aponta que $58 \%$ dos brasileiros acessam a rede exclusivamente pelo celular. Além disto, no que se refere à conexão domiciliar, a internet está presente em $71 \%$ dos domicílios brasileiros. Logo, é preciso pensar em soluções que possam ser efetivas na maior parte da população de estudantes. Nas abordagens I, II e III, as tecnologias adotadas, a exemplo: Moodle, Meet e Overleaf, dispõem de interfaces voltadas para computação móvel, tornando o conteúdo acessível para maior parte dos estudantes. Sobretudo, o celular pode não ser o melhor meio para acessar aulas e materiais de estudos, porém, para muitos é a única alternativa.

\section{Conclusão e Trabalhos Futuros}

Neste estudo, foi utilizada uma metodologia baseada em sala de aula invertida, PBL e gamification com três abordagens distintas. Uma quarta abordagem totalmente voltada para o ensino remoto também foi discutida.

O processo de sala de aula invertida está presente em todas as abordagens da metodologia, que inclui o uso extensivo de artefatos (vídeos, materiais de ensino e referências bibliográficas), permitindo aos alunos mais liberdade para criar seus horários de estudo. Foi possível perceber uma melhora no desempenho dos alunos, assim como descrito em (Paschoal, Silva, \& Souza, 2017) e também uma melhora no conteúdo prático e debates mais construtivos nas discussões em grupo. Porém, com feedback negativo de aproximadamente $28 \%$ sobre os EDs e de $25 \%$ sobre os vídeos sugeridos, é preciso uma maior atenção sobre os artefatos disponibilizados aos alunos, haja vista que em (Araujo, Viana, Veras, \& de Castro Filho, 2018) os autores afirmam que a qualidade do material é um fator essencial para o desempenho satisfatório dos alunos na metodologia de aula invertida.

Entre os benefícios do gamification, de acordo com (Alves, 2015), estão: i) tornar o processo de aprendizagem mais atraente, ii) desenvolver autonomia e iii) estimular a concorrência saudável. Tais benefícios foram verificados durante as abordagens, resultando em maior motivação por parte dos alunos. Por exemplo, na etapa de discussão dos EDs, observou-se um maior interesse e participação dos alunos.

A aplicação de PBL esteve presente na modelagem da fase de desenvolvimento, na qual os alunos resolvem os problemas propostos pelo professor para aplicar e internalizar o conteúdo que estudaram fora da classe, incentivando os alunos a resolver problemas práticos e gerando resultados positivos, assim como os vistos também em (Acosta, 2016). Foi perceptível que houve um aumento efetivo da atenção às aulas e o comprometimento nas soluções para os desafios que lhes foram apresentados. Como alguns grupos não puderam trabalhar coletivamente, o monitoramento do professor foi essencial para reverter essa situação.

A metodologia proposta é representada em uma nova meta-arquitetura como um diagrama, permitindo sua replicação em outros cenários. A abordagem IV é sugerida como uma proposta de

\footnotetext{
${ }^{18}$ https://cetic.br/pt/tics/domicilios/2019/individuos/
} 
ensino para IEs durante o período de pandemia no qual as aulas presenciais estão suspensas até nova ordem das entidades de administração superiores.

A abordagem IV para aulas remotas, foi formulada utilizando os softwares disponíveis no mercado, juntamente com a experiência das abordagens anteriores (I, II e III). Acredita-se que a metodologia possa ser replicada para outras Instituições de Ensino Superior (IEs) por se tratar de um processo modular e flexível, onde partes do processo podem ser adaptadas à realidade do contexto. A efetividade da abordagem IV requer validação, assim como foi feito com as demais abordagens. Essa validação se iniciou a partir de agosto deste ano, mas ainda não foi concluída.

Como trabalho futuro, pretende-se aplicar a metodologia em outras turmas de modo a verificar se os resultados da sua aplicação tendem a ter melhores resultados ou não. Além disso, pretende-se identificar outras técnicas que permitam a inclusão de novos artefatos no processo, enriquecendo ainda mais a metodologia ou, na pior das hipóteses, simplificando o processo.

A abordagem III foi, sem dúvida, a mais encorajadora do estudo, pois foi possível identificar que quanto mais tempo o aluno passa focado em uma disciplina a hipótese dele se sair bem é mais evidente. Alguns alunos argumentaram que a diminuição das avaliações (ED e avaliação de classe) para um modelo que pudesse unificar os dois processos ou até eliminá-los, poderia trazer mais benefícios a metodologia. Os estudantes queixaram-se de um grande número de atividades. Isso foi sentido principalmente na abordagem II e III, mas acredita-se que essas avaliações são de fundamental importância para acompanhar o desenvolvimento cognitivo e a absorção de conteúdo pelo aluno nos estudos em sala de aula.

\section{Agradecimentos}

O presente trabalho foi realizado com apoio da Coordenação de Aperfeiçoamento de Pessoal de Nível Superior - Brasil (CAPES) - Código de Financiamento 001.

\section{Referências}

Acosta, O. C. (2016). Recomendação de conteúdo em um ambiente colaborativo de aprendizagem baseada em projetos (Doctoral thesis, UFRGS, Rio Grande do Sul, Brazil). Disponível em http://hdl.handle.net/10183/148295 [GS Search]

Adams, N. E. (2015). Bloom's taxonomy of cognitive learning objectives. Journal of the Medical Library Association: JMLA, 103(3), 152. 10.3163/1536-5050.103.3.010 [GS Search]

Akçayır, G., \& Akçayır, M. (2018). The flipped classroom: A review of its advantages and challenges. Computers \& Education, 126, 334-345. doi: https://doi.org/10.1016/j.compedu.2018.07.021 [GS Search]

Alves, f. (2015). Gamification; Como criar experiências de aprendizagem engajadoras (2nd ed.). São Paulo, São Paulo: DVS Editora.

Ambrósio, A. P. L., \& Costa, F. M. (2010, March). Evaluating the impact of PBL and tablet PCs in an algorithms and computer programming course. In Proceedings of the 41st ACM technical symposium on Computer science education (pp. 495-499). doi: $\underline{10.1145 / 1734263.1734431}$ [GS Search]

Anazifa, R., \& Djukri, D. (2017). Project-based learning and problem-based learning: Are they effective to improve student's thinking skills? Jurnal Pendidikan IPA Indonesia, 6(2), 346355. [GS Search] 
Araujo, P., Viana, W., Veras, N., \& de Castro Filho, J. A. (2018, October). Aprendizagem Adaptativa em Aulas Invertidas de Sistemas Distribuídos: um estudo de caso apoiado no G Suite. In Brazilian Symposium on Computers in Education (Simpósio Brasileiro de Informática na Educação-SBIE) (Vol. 29, No. 1, p. 328). doi: 10.5753/cbie.sbie.2018.328 [GS Search]

Argaw, A. S., Haile, B. B., Ayalew, B. T., \& Kuma, S. G. (2017). The effect of problem based learning (pbl) instruction on students' motivation and problem solving skills of physics. EURASIA Journal of Mathematics Science and Technology Education, 13(3), 857-871. doi: 10.12973/eurasia.2017.00647a [GS Search]

Baepler, P., Walker, J., \& Driessen, M. (2014). It's not about seat time: Blending, flipping, and efficiency in active learning classrooms. Computers \& Education, 78, 227-236. doi: 10.1016/j.compedu.2014.06.006 [GS Search]

Barrows, H. S., Tamblyn, R. M., et al. (1980). Problem-based learning: An approach to medical education (Vol .1). New York. Springer Publishing Company. [GS Search]

Bell, S. (2010). Project-based learning for the 21st century: Skills for the future. The Clearing House: A Journal of Educational Strategies, Issues and Ideas, 83(2), 39-43. doi: $\underline{10.1080 / 00098650903505415}$ [GS Search]

Bergmann, J., \& Sams, A. (2012). Flip your classroom: Reach every student in every class every day. International society for technology in education. Washington, DC. [GS Search]

Berrett, D. (2012). How 'flipping' the classroom can improve the traditional lecture. The chronicle of higher education, 12(19), 1-3. Disponível em https://www.chronicle.com/article/howflipping-the-classroom-can-improve-the-traditional-lecture/ [GS Search]

Bloom, B. S., Hastings, J. T., \& Madaus, G. F. (1971). Handbook on formative and summative evaluation of student learning. New York: McGraw-Hill. Disponível em https://www.amazon.com/Handbook-Formative-Summative-EvaluationLearning/dp/0070061149 [GS Search]

Brown, J. F., \& Marshall, B. L. (2008). Continuous quality improvement: An effective strategy for improvement of program outcomes in a higher education setting (Vol. 29). Nursing Education Perspectives, 29(4), 205-211. [GS Search]

Carter, M. (2009). Visible learning: a synthesis of over 800 meta-analyses relating to achievement. Educational Psychology, 29(7), 867-869. doi: 10.1080/01443410903415150 [GS $\underline{\text { Search }}$

Conklin, J. (2005). A taxonomy for learning, teaching, and assessing: A revision of bloom's taxonomy of educational objectives complete edition. Educational Horizons, 83(3), 154-159. Retrieved October 23, 2020. Disponível em http://www.jstor.org/stable/42926529 [GS Search]

De Grazia, J. L., Falconer, J. L., Nicodemus, G., \& Medlin, W. (2012, June). Incorporating screencasts into chemical engineering courses. In 2012 ASEE Annual Conference \& Exposition (pp. 25-762). doi: 10.18260/1-2--21519 [GS Search]

Ergül, N. R., \& Kargın, E. K. (2014). The effect of project based learning on students' science success. Procedia-Social and Behavioral Sciences, 136, 537-541. Disponível em http://www.sciencedirect.com/science/article/pii/S187704281403852X doi: $\underline{10.1016 / \text { j.sbspro.2014.05.371 [GS Search] }}$ 
Ferraz, A. P. d. C. M., \& Belhot, R. V. (2010). Taxonomia de bloom: revisão teórica e apresentação das adequações do instrumento para definição de objetivos instrucionais. Gestão \& Produção, 17(2), 421-431. doi: 10.1590/S0104-530X2010000200015 [GS Search]

Galhardi, A. C., \& Azevedo, M. M. D. (2013, October). Avaliações de aprendizagem: o uso da taxonomia de Bloom. In Anais do VII Workshop Pós-graduação e Pesquisa do Centro Paula Souza, São Paulo (Vol. 1, No. 1, pp. 237-247). Disponível em http://www.pos.cps.sp.gov.br/files/artigo/file/507/ad7a753c51e25c1529d318820a756dd2.pd $\underline{\mathrm{f}}$ [GS Search]

Gibbons, T. E. (2013, October). COR: a new course framework based on elements of game design. In Proceedings of the 14th annual ACM SIGITE conference on Information technology education (pp. 77-82). doi: 10.1145/2512276.2512292 [GS Search]

Govindaraj, A., \& Silverajah, V. G. (2017, December). Blending Flipped Classroom and Station Rotation Models in Enhancing Students' Learning of Physics. In Proceedings of the 2017 9th International Conference on Education Technology and Computers (pp. 73-78). doi: $\underline{10.1145 / 3175536.3175543}$ [GS Search]

Hertz, M. (2010, March). What do" CS1" and" CS2" mean? Investigating differences in the early courses. In Proceedings of the 41st ACM technical symposium on Computer science education (pp. 199-203). doi: 10.1145/1734263.1734335 [GS Search]

Jong, M. S. Y. (2017). Empowering students in the process of social inquiry learning through flipping the classroom. Journal of Educational Technology \& Society, 20(1), 306-322. Disponível em http://www.jstor.org/stable/jeductechsoci.20.1.306 [GS Search]

Khan, M., Hossain, S., \& Abdou, B. (2020). Flipped Classroom: How Institutions of Higher Education (HEIs) of Bangladesh Could Move Forward During Covid-19 Pandemic. Social Sciences Humanities Open. doi: 10.2139/ssrn.3615400 [GS Search]

Koh, J. H. L. (2019). Four pedagogical dimensions for understanding flipped classroom practices in higher education: A systematic review. Educational Sciences: Theory \& Practice, 19(4), 14-33. doi: $\underline{10.12738 / \text { estp.2019.4.002 [GS Search] }}$

Lai, C.-L., \& Hwang, G.-J. (2016). A self-regulated flipped classroom approach to improving students' learning performance in a mathematics course. Computers \& Education, 100, 126140. doi: 10.1016/j.compedu.2016.05.006 [GS Search]

Latulipe, C., Long, N. B., \& Seminario, C. E. (2015, February). Structuring flipped classes with lightweight teams and gamification. In Proceedings of the 46th ACM Technical Symposium on Computer Science Education (pp. 392-397). doi: 10.1145/2676723.2677240 [GS Search]

Lo, C. K., \& Hew, K. F. (2017). A critical review of flipped classroom challenges in K-12 education: Possible solutions and recommendations for future research. Research and practice in technology enhanced learning, 12(1), 4. doi: 10.1186/s41039-016-0044-2 [GS Search]

Mason, G. S., Shuman, T. R., \& Cook, K. E. (2013). Comparing the effectiveness of an inverted classroom to a traditional classroom in an upper-division engineering course. IEEE transactions on education, 56(4), 430-435. doi: 10.1109/TE.2013.2249066 [GS Search]

Mokmin, N. A. M., Masood, M., \& Osman, S. Z. (2019, March). The Adoption of Flipped Classroom Model for Malaysian TVET Institutions. In Proceedings of the 2019 7th International Conference on Information and Education Technology (pp. 204-208). doi: $\underline{10.1145 / 3323771.3323781}$ [GS Search] 
Munir, M. T., Baroutian, S., Young, B. R., \& Carter, S. (2018). Flipped classroom with cooperative learning as a cornerstone. Education for Chemical Engineers, 23, 25-33. doi: 10.1016/i.ece.2018.05.001 [GS Search]

Naw, N. (2020). Designing a flipped classroom for myanmar universities during covid-19 crisis. Arts Science Engineering, Economic and Education, 1. Disponível em https://www.researchgate.net/publication/342563551_Designing_a_Flipped_Classroom_for Myanmar Universities during COVID-19 Crisis

Nicésio, A., Almeida, M. B. d., \& Conceição, L. M. d. Políticas públicas na educação básica. Ed. S.A, Londrina, 2015. Editora e Distribuidora Educacional S.A. Disponível em https://s3.amazonaws.com/cm-klscontent/201502/INTERATIVAS 2 0/POLITICAS PUBLICAS NA EDUCACAO BASI CA/U1/LIVRO_UNICO.pdf

Nuutila, E., Törmä, S., \& Malmi, L. (2005). Pbl and computer programming-the seven steps method with adaptations. Computer Science Education, 15(2), 123-142. doi: $\underline{10.1080 / 08993400500150788}$ [GS Search]

O'Flaherty, J., \& Phillips, C. (2015). The use of flipped classrooms in higher education: A scoping review. The internet and higher education, 25,85-95. doi: 10.1016/j.iheduc.2015.02.002 [GS Search]

de Souza Ortiz, J. O., \& Dorneles, A. M. (2018). Uso da taxonomia de Bloom digital gamificada em atividades coletivas no ensino de química: reflexões teóricas e possibilidades. Revista Eletrônica Ludus Scientiae, 2(2). doi: 10.30691/relus.v2i2.1475 [GS Search]

Paschoal, L. N., Silva, L., \& Souza, S. (2017, October). Abordagem flipped classroom em comparação com o modelo tradicional de ensino: uma investigação empírica no âmbito de teste de software. In Brazilian Symposium on Computers in Education (Simpósio Brasileiro de Informática na Educação-SBIE) (Vol. 28, No. 1, p. 476). doi: 10.5753/cbie.sbie.2017.476 [GS Search]

Pierce, R., \& Fox, J. (2012). Vodcasts and active-learning exercises in a "flipped classroom" model of a renal pharmacotherapy module. American journal of pharmaceutical education, 76(10). doi: 10.5688/ajpe7610196 [GS Search]

Rahman, A. A., Aris, B., Mohamed, H., \& Zaid, N. M. (2014, December). The influences of flipped classroom: A meta analysis. In 2014 IEEE 6th Conference on Engineering Education (ICEED) (pp. 24-28). IEEE. doi: 10.1109/ICEED.2014.7194682 [GS Search]

Rutherfoord, R. H., \& Rutherfoord, J. K. (2013, October). Flipping the classroom: Is it for you?. In Proceedings of the 14th annual ACM SIGITE conference on Information technology education (pp. 19-22). doi: 10.1145/2512276.2512299 [GS Search]

Sappington, J., Kinsey, K., \& Munsayac, K. (2002). Two studies of reading compliance among college students. Teaching of Psychology, 29(4), 272-274. doi: 10.1207/S15328023TOP2904_02 [GS Search]

Savi, R., \& Ulbricht, V. R. (2008). Jogos digitais educacionais: benefícios e desafios. RENOTERevista Novas Tecnologias na Educação, 6(1). Disponível em https://www.seer.ufrgs.br/renote/article/viewFile/14405/8310 [GS Search]

Solomon, G. (2003). Project-based learning: A primer. TECHNOLOGY AND LEARNINGDAYTON-, $\quad 23(6), \quad 20-20 . \quad$ Disponível em https://free.openeclass.org/modules/document/file.php/ENG155/Projects\%20online/PBLPrimer-www techlearning_com.pdf [GS Search] 
Sun, J. C. Y., Wu, Y. T., \& Lee, W. I. (2017). The effect of the flipped classroom approach to OpenCourseWare instruction on students' self-regulation. British Journal of Educational Technology, 48(3), 713-729. doi: 10.1111/bjet.12444 [GS Search]

Waller, M. A., \& Fawcett, S. E. (2013). Data science, predictive analytics, and big data: a revolution that will transform supply chain design and management. Journal of Business Logistics, 34(2), 77-84. doi: 10.1111/JBL.12010 [GS Search]

Werbach, K., \& Hunter, D. (2015). The gamification toolkit: dynamics, mechanics, and components for the win. Wharton School Press.

WHO. (2020). Coronavirus disease (COVID-19) pandemic. Disponível em https://www.who.int/emergencies/diseases/novel-coronavirus-2019

Wolf, A., Wilhelm-Weidner, A., \& Nestmann, U. (2018). A case study of flipped classroom for automata theory in secondary education. Proceedings of the 13th Workshop in Primary and Secondary Computing Education on - WiPSCE '18. doi: 10.1145/3265757.3265780 [GS Search]

Zhang, D., Zhou, L., Briggs, R. O., \& Nunamaker Jr, J. F. (2006). Instructional video in elearning: Assessing the impact of interactive video on learning effectiveness. Information \& management, 43(1), 15-27. doi: 10.1016/j.im.2005.01.004 [GS Search]

\section{Apêndice}

\section{Questionário (Quiz) Avaliação da Disciplina}

As questões foram elaboradas tentando estabelecer duas respostas positivas geralmente ("a" e "b"), 1 neutra ("c") e duas negativas ("d" e "e") buscando usar uma linguagem mais informal com o objetivo de obter respostas o mais autênticas possíveis.

1. Após cursar a disciplina Inteligência Artificial, este tema: a) Me fascina. b) Me interessa. c) Não me motiva muito. d) É interessante, mas não me motiva. e) Não me interessa.

2. Com relação à metodologia de "aulas invertidas", isto é, o aluno estuda a parte teórica fora da sala de aula e utiliza o tempo em classe para atividades práticas: a) Acho que é excelente. b) Acho que é boa. c) Tanto faz. d) Não me agrada. e) Acho péssima.

3. Com relação aos EDs: a) É uma técnica muito interessante e me ajudou a compreender a parte teórica. b) Toma muito tempo do aluno. Por isso, fica difícil responder as questões.

c) $\mathrm{O}$ professor deveria propor as questões e também fornecer as respostas. d) Acho que o estudo da teoria em livros é desnecessário. Há muitos resumos na internet. e) Acho desnecessário estudar a teoria. Deveríamos ir direto para os trabalhos práticos.

4. Ao comparar as avaliações feitas em classe (no formato verdadeiro ou falso) com a avaliação por meio de questões abertas, considero: a) Muito melhores. b) Melhores. c) Tanto faz. d) Piores. e) Muito piores.

5. Ainda com relação às avaliações feitas em classe, considero que: a) Foram bem elaboradas. b) Poderiam ser melhor elaboradas. c) Deveriam ser de múltiplas escolhas e não de V/F. d) Deveriam ser substituídas por questões discursivas. e) Não deveria haver avaliações em classe.

6. Com relação às propostas de trabalho em classe: a) Foram excelentes. b) Foram boas. c) Poderiam ser melhor elaboradas. d) Não foram nada interessantes. e) Totalmente 
desmotivantes.

7. Com relação ao meu desempenho nos trabalhos em classe: a) Não tive nenhuma dificuldade. b) Tive dificuldades, mas consegui fazê-los. c) Tive uma grande dificuldade. d) Não consigo fazer esse tipo de trabalho sozinho. e) Não consigo fazer esse tipo de trabalho.

8. Com relação aos vídeos sugeridos no curso: a) Excelentes. Foram fundamentais para meu aprendizado. b) Contribuíram para meu aprendizado, mas aprendi mais com os textos escritos. c) Não contribuíram com nada. Foi perda de tempo assisti-los. d) Não tive tempo de vê-los. Os demais trabalhos consumiram todo o meu tempo disponível. e) Prefiro apenas ler os livros.

9. Minha maior dificuldade com os trabalhos em classe foi: a) Não tive dificuldades. b) Tive dificuldades por não entender bem a especificação do trabalho. c) Tive dificuldades por não conhecer a linguagem Python. d) Tive dificuldades por que o trabalho envolvia programação. e) Tive dificuldades por que não consigo fazer implementações sobre pressão (com tempo determinado e fora do meu local particular de estudo).

10. Com relação ao meu empenho na disciplina: a) Me empenhei ao máximo em fazer todas as atividades. b) Me empenhei, mas não tive tanto tempo quanto gostaria. c) Estava com atividades demais no curso. Não pude me empenhar. d) Não me empenhei como deveria. e) Não me interessei em aprender o conteúdo, mas preciso passar.

11. Após cursar a disciplina, considero que: a) Aprendi muito bem os tópicos propostos. b) Acredito que aprendi a maioria dos tópicos. c) Não consegui aprender muita coisa. d) Tive muitas dificuldades. e) Talvez precise cursar a disciplina novamente.

12. Na sua opinião, a metodologia usada na disciplina, em comparação com outras metodologias utilizadas nas disciplinas que você já fez: a) É muito melhor e deveria ser replicada. b) É boa para IA, mas não deveria ser aplicada em outras disciplinas. c) É boa, mas precisa ser aprimorada. d) Não me pareceu nem melhor nem pior que as outras metodologias. e) Prefiro a forma tradicional, com o professor apresentando o conteúdo em sala de aula.

13. Apresente aqui suas críticas com relação à metodologia utilizada na disciplina, isto é, aquilo que não lhe agradou.

14. Use este espaço para apresentar sugestões que possam contribuir com a melhoria da metodologia utilizada em IA. 